\title{
Recycling/reuse of plastic waste as construction material for sustainable development: a review
}

\author{
Pooja Lamba ${ }^{1}$. Dilraj Preet Kaur ${ }^{1}$ (1) $\cdot$ Seema Raj $^{1} \cdot$ Jyoti Sorout ${ }^{1}$
}

Received: 31 May 2021 / Accepted: 6 October 2021 / Published online: 16 October 2021

(c) The Author(s), under exclusive licence to Springer-Verlag GmbH Germany, part of Springer Nature 2021

\begin{abstract}
The exponential rise in the production of plastic and the consequential surge in plastic waste have led the scientists and researchers look out for innovative and sustainable means to reuse/recycle the plastic waste in order to reduce its negative impact on environment. Construction material, converting waste plastic into fuel, household goods, fabric and clothing are some of the sectors where waste plastic is emerging as a viable option. Out of these, construction material modified with plastic waste has garnered lot of attention. Modification of construction material with plastic waste serves a dual purpose. It reduces the amount of plastic waste going to landfills or litter and secondly lessens the use of mined construction materials, thereby mitigating the negative impact of construction industry on environment. This paper summarizes the developments with regard to the use of plastic waste as a constituent of construction material. Inclusion of plastic waste as a binder, aggregate, fine aggregate, modifier or substitute of cement and sand in the manufacturing of bricks, tiles, concrete and roads has been comprehensively reviewed. Also, the influence of addition of plastic waste on strength properties, water absorption, durability, etc. has been thoroughly discussed. The research studies considered for this review have been categorized based on whether they dealt with the use of plastic waste for bricks and tiles or in concrete for road construction.
\end{abstract}

Keywords Plastic waste $\cdot$ Bricks $\cdot$ Tiles $\cdot$ Concrete $\cdot$ Construction material $\cdot$ Sustainability

\section{Introduction}

Accumulation of plastic waste over the years and the lack of suitable disposal techniques have given rise to a crucial and unparalleled crisis where plastic waste is clogging our water resources and waterways, overflowing the landfills, leaching into soil and transferring through air, thus polluting every natural resource in our environment. Longevity; which is one of the most beneficial features of plastic, is also a detrimental factor in its safe disposal. In reality, plastic materials never degrade completely but disintegrate into smaller pieces over hundreds of years. According to a report by the United Nations Environment Programme, around 300 million tonnes of plastic waste is generated every year globally, whereas plastic waste ever recycled merely counts to $9 \%$. A statement by UNEP executive director Inger Andersen:

Responsible Editor: Philippe Garrigues

Dilraj Preet Kaur

dilraj.k@krmangalam.edu.in

1 K. R. Mangalam University, Gurugram, Haryana, India
'By 2050, we will have about a billion metric tons of plastic in our landfills. We need to make a shift'.

presents a grim reality of the current scenario (https:// www.unep.org/news-and-stories/story/plastic-recyclingunderperforming-sector-ripe-remake. Accessed 28 May 2021). The COVID-19 pandemic has further thrashed the efforts for reducing plastic pollution, where the disposal of used PPE kits, gloves, masks, sanitizer dispensers, etc. has created a scenario of 'pandemic of plastic pollution'.

In the past few years, the plastic production has increased manifold and so does the plastic waste, but the problematic issue is that most of the plastic waste is going to the landfills or clogging our water bodies. Figure 1 shows the worldwide production of plastic in the recent past, and Fig. 2 depicts the scenario of plastic waste management.

Owing to the beneficial properties such as longevity, lightweight, water resistant, high elasticity, strength, durability, resistant to corrosion, easy to transport and economical, plastics are otherwise highly useful materials. However, it is the overconsumption of plastic which is creating havoc. Plastics have become an indispensable part of our lives, so the only sustainable solution in sight to reduce plastic 


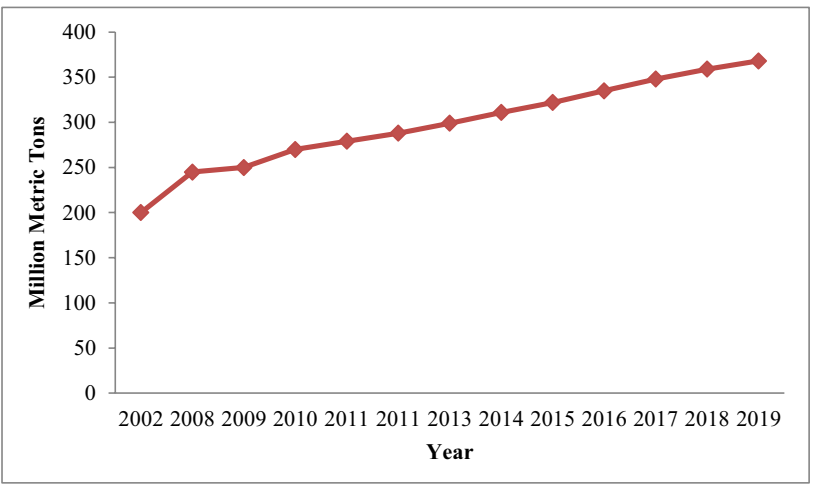

Fig. 1 Worldwide production of plastic

pollution is to maximize its recycling and reuse. There are many sectors where we can use the waste plastic or recycle it for further application vis-à-vis construction material, converting waste plastic into fuel, household goods, fabric and clothing, shoe soles, etc. The aim of the present study is to review comprehensively the utilization of plastic waste as a construction material. This paper analyses different research approaches that employ plastic waste as binder, aggregate, fine aggregate, modifier or substitute of cement and sand in the manufacturing of bricks, tiles and concrete.

\section{Past reviews and gap}

Recently, many reviews have been reported based on investigating the use of diverse types of waste materials in construction. In 2016, Tiwari et al. presented a review assessing different industrial waste products such as bottom ash, waste foundry sand, copper slag, plastic waste, recycled rubber waste and crushed glass aggregate as a replacement of fine aggregates in concrete (Tiwari et al. 2016). Guand Ozbakkaloglu summarized the studies on recycling techniques of plastic waste and the effect of its addition on the characteristics and morphology of concrete (Gu and Ozbakkaloglu 2016). In 2018, Toghroli et al. reviewed the usage of recycled waste materials in pavement concrete. The reviewed waste materials include recycled crushed glass, steel slag, steel fibre, tyres, plastics and recycled asphalt (Toghroli et al. 2018). Babafemi et al. presented a review on the properties of concrete incorporated with waste recycled plastic. It has shown the effect of recycled waste plastic on the mechanical properties and durability (Babafemi et al. 2018). There was also a detailed review of the properties of mortar and concrete composites containing recycled plastic (Mercante et al. 2018). Singh et al. critically reviewed the use of polyethylene terephthalate (PET) and marble dust in composites for construction (Singh et al. 2021). Another review reported PET plastic bricks used for Rohingya refugee camp (Haque 2019). Salih et al. reviewed the progress on bricks reinforced with fibres derived from waste materials (Salih et al. 2020). Bejan et al. presented the review on lightweight concrete using various waste materials, such as fly ash, blast furnace slag, fumed silica, tyre waste, plastics and agro waste (Bejan et al. 2020). Awoyera and Adesina presented a detailed review of the use of plastic waste as a constituent in cement composites. They also discussed the limitations and future prospects of using plastic waste (Awoyera and Adesina 2020). Li. et al. studied in detail about the effect of addition of rubber and plastic waste as an aggregate to the concrete ( $\mathrm{Li}$ et al. 2020). Another review on the utilization of plastic waste as an aggregate in construction material and the effect on mechanical and durability properties was recently presented (Zulkernain et al. 2021). Vishnu and Singh presented a review on suitability of various waste materials for

Fig. 2 Scenario of plastic waste management

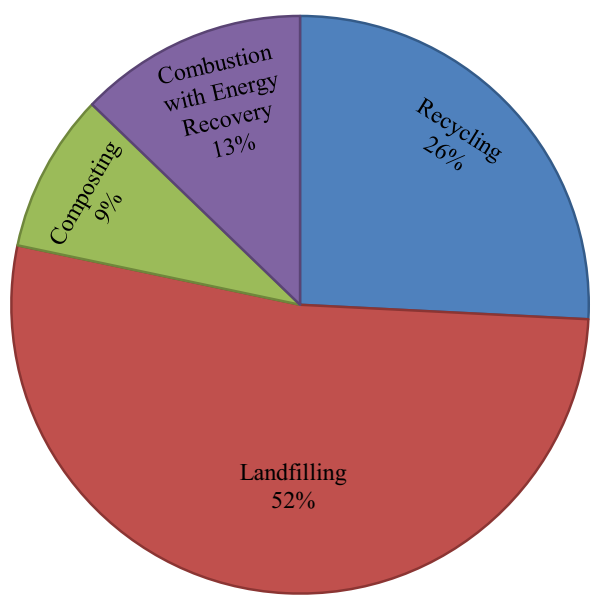


bituminous pavements (Vishnu and Singh 2020). Ogundairo et al. reviewed the use of plastic in bitumen modification and stabilization of soil and as reinforcement material in bricks (Ogundairo et al. 2021). From the above discussion, it is evident that some researchers have covered plastic waste as a scope of their study whereas others have covered it partially. Though there are many reviews, however, a detailed study on the incorporation of plastic waste in different aspects of construction material is missing. There is much scope in the analysis of different types of plastic waste that has been used across various sectors of construction material vis-à-vis in bricks, tiles, blocks, concrete and road construction. Realising this, we are presenting an exhaustive review on the range of plastic waste materials such as polythene, polypropylene (PP), polyethylene terephthalate (PET), high-density polythene (HDPE), low-density polythene (LDPE) and polyvinyl chloride (PVC) and their suitability for inclusion in the manufacturing of bricks, tiles, construction blocks and concrete for road construction. This review paper also presents the influence of plastic waste on the strength and durability of the end products.

\section{Types of plastic}

A variety of plastics are available in the market for diverse applications. However, only some plastics can be recycled, which falls under the category of thermoplastics, e.g. PET (polyethylene terephthalate), HDPE (high-density polyethylene), LDPE (low-density polyethylene), PVC (polyvinyl chloride), PP (polypropylene) and PS (polystyrene). The non-recyclable plastic is under the category of thermosetting plastics and synthetic fibres, e.g. multilayer and laminated plastic, Teflon, PUF (polyurethane foam), Bakelite, polycarbonate, melamine and nylon. Figure 3 shows the classification of different plastics and their suitable applications.

Based on particle size, plastics are classified as:

- Nanoplastics: particle size $<0.0001 \mathrm{~mm}$

- Small microplastics: particle size 0.00001-1 mm

- Large microplastics: particle size $1-4.75 \mathrm{~mm}$

- Mesoplastics: particle size 4.76-200 mm

- Macroplastics: particle size $>200 \mathrm{~mm}$

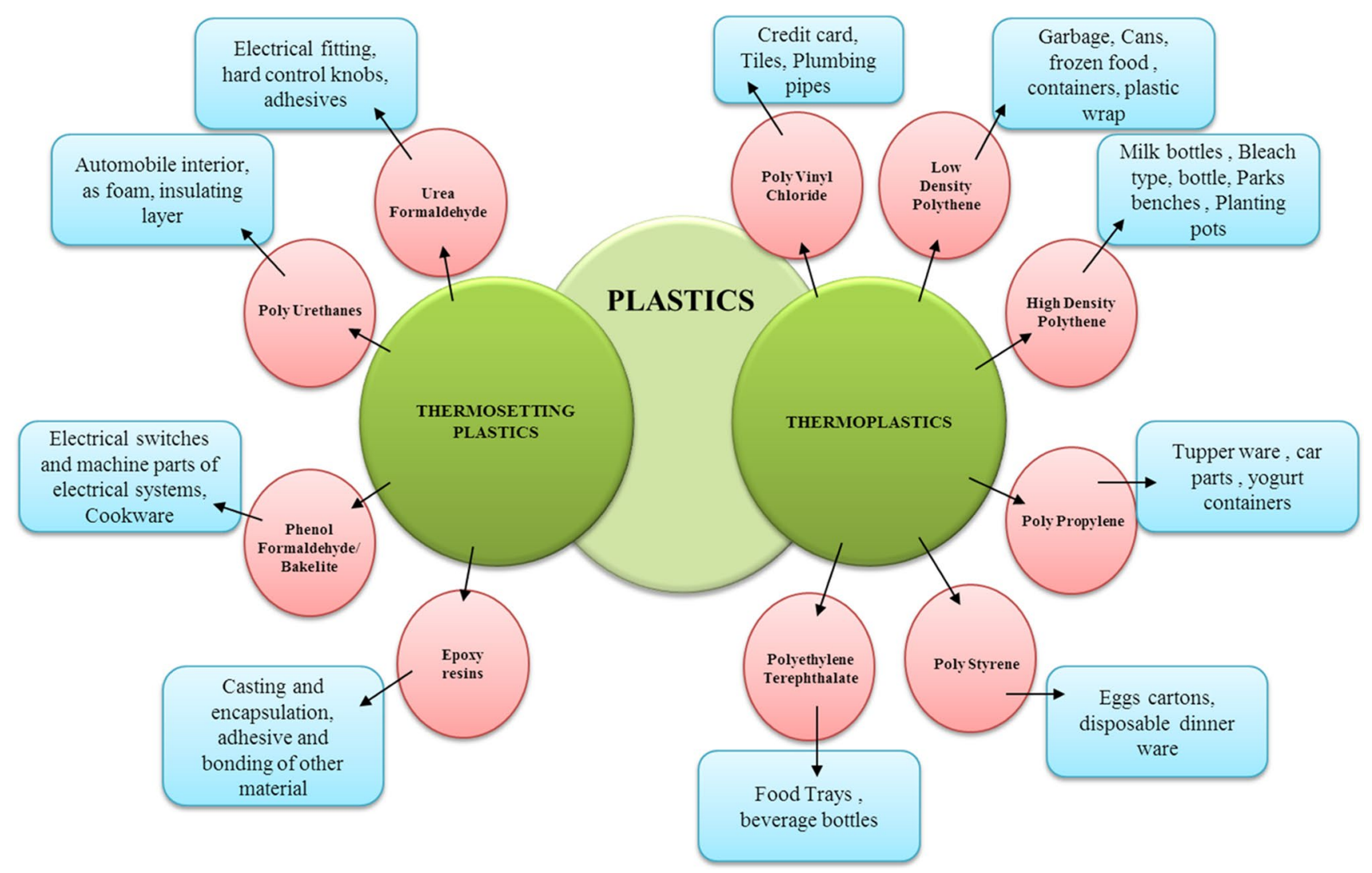

Fig. 3 Classification of different types of plastics and suitable applications 


\section{Utilization of plastic waste in construction bricks, tiles and blocks}

This section reviews the modification of masonry bricks/ tiles/blocks with plastic waste. We have done a detailed study to accommodate all perspectives of plastic waste utilization in construction bricks, tiles and blocks, along with quantitative analysis.

In a study, polyethylene terephthalate (PET) scrap plastic wastes (SPW) and foundry sand (FS) were used in the construction of green productive bricks. They mixed FS and SPW in percentages of 80:20, 70:30 and 60:40 of the dry mass. The bricks were soaked in acid and water to check the toughness, and compressive and tensile strength tests examined the strength. Bricks with (SF: SPW =70:30) showed the maximum compressive strengths of $38.14 \mathrm{MPa}$ and tensile strength of $9.51 \mathrm{MPa}$ (Aneke and Shabangu 2021). Another report suggested that the use of recycled crushed glass (RCG) along with PET plastic waste (PPW) in varying percentages of 80:20, 70:30 and 60:40 of RCG and PPW enhanced the tensile strength and compressive strength by $70.15 \%$ and $54.85 \%$, respectively, compared to the strength of conventional clay bricks. The average compressive strength and tensile strength obtained were $42.01 \mathrm{MPa}$ and $9.89 \mathrm{MPa}$, respectively, and the average water absorption value was only $2.7 \%$. Because of high hydrophobic properties, both types of masonry bricks made from foundry sand and crushed glass do not need water for construction, were more resistant to chemical attack and were less deformable under strain stress as compared to burnt clay bricks (Ikechukwu and Shabangu 2021).

Compacted earth blocks (CEB) were made from clayey sand and PET waste in shredded form mixed in various percentages $(0,1,3$, and $7 \%)$. The mixture was tested for explicit gravity, molecule size dispersion, Atterberg limits and compaction to evaluate the properties of soil. The results showed that the compressive strength of CEB was poor, i.e. $0.45 \mathrm{MPa}$ without any additive. The CEB containing $1 \%$ of plastic waste of size $6.3 \mathrm{~mm}$ showed the highest compressive strength with an increment of $244.4 \%$. The disintegration rate was lowest in the test involving $1 \%$ plastic waste with size less than $6.3 \mathrm{~mm}$. The findings of the Atterberg limits showed that the soil fines have a low pliancy. A binder such as cement, lime or any material with cementitious nature was mixed with the soil and shredded waste plastic during the CEB production process to improve the compressive strength and sturdiness (Akinwumi et al. 2019).

As an alternative to traditional bricks, authors suggested the use of construction and demolition waste and plastic bottles. They filled the used plastic bottles with compressed recycled aggregates (RA) with water content as $0,2.5,5,7.5$ and $10 \%$. Bottles containing crushed RA of size less than $425 \mu \mathrm{m}$ exhibited higher compressive strength $\left(15.25 \mathrm{~N} / \mathrm{mm}^{2}\right)$ than those containing RA of a size between 425 and $4.75 \mu \mathrm{m}\left(9.84 \mathrm{~N} / \mathrm{mm}^{2}\right)$ with a $5 \%$ water content. The compressive strength at $5 \%$ water content was comparable with the compressive strength of conventional red clay brick $\left(17 \mathrm{~N} / \mathrm{mm}^{2}\right)$ and fly ash brick $\left(12 \mathrm{~N} / \mathrm{mm}^{2}\right)$ (Lalzarliana Paihte et al. 2019). Another report suggested the manufacturing of construction units from plastic bottles (PET) filled with either dry sand, saturated sand or air, with cement mortar acting as a binder. The resulting solid masonry walls were having low thermal conductivity. Bottle blocks packed with dry sand showed a compressive strength of $623 \mathrm{kN} / \mathrm{m}^{2}$ and a bulk unit weight of $17.67 \mathrm{kN} /$ $\mathrm{m}^{3}$, whereas bottle blocks filled with saturated sand had a compressive strength of $609 \mathrm{kN} / \mathrm{m}^{2}$ and a bulk unit weight of $19.59 \mathrm{kN} / \mathrm{m}^{3}$, and air-filled bottle blocks showed compressive strength of $670 \mathrm{kN} / \mathrm{m}^{2}$ and a bulk unit weight of $11.02 \mathrm{kN} / \mathrm{m}^{3}$. Although the gross strength of these plastic bottle blocks $\left(670 \mathrm{kN} / \mathrm{m}^{2}\right)$ was significantly lower than that of standard blocks $\left(3670 \mathrm{kN} / \mathrm{m}^{2}\right)$, still the blocks of air-filled bottles could prove useful as partition walls or as bearing walls for a single roof slab. In terms of thermal insulation, air-filled bottles outperformed traditional construction blocks, which may serve as a thermal insulator (Mansour and Ali 2015). Another researcher placed waste plastic bags inside $500 \mathrm{~mL}$ PET bottles to make eco-bricks. After packaging, the weight of the eco-brick must not be less than $220 \mathrm{~g}$. They compared these bricks to traditional bricks in terms of compression, sound isolation and light transmission. These eco-bricks exhibited a high sound reduction index and withstood a maximum compression force of $40.1 \mathrm{kN}$, giving them a resistance of 2.96 MPa. The value of Poisson's ratio was between 0.27 and 0.35 range (Taaffe et al. 2014). Plastic waste bottles were also used in the manufacturing of concrete blocks. For this purpose, authors compared the traditional hollow concrete blocks having dimensions $200 \times 200 \times 400 \mathrm{~mm}$ (purchased from market) and concrete blocks of same size embedded with plastic bottles. The standard hollow blocks had an average weight of $20.08 \mathrm{~kg}$ and a compressive strength of $6.38 \mathrm{MPa}$ after 28 days, but the plastic bottle block had a weight of $24.85 \mathrm{~kg}$ and a compressive strength of $10.03 \mathrm{MPa}$. According to the findings, using waste plastic bottles in concrete block masonry not only helps to solve the problem of finding a new use for plastic waste, but it also improves the masonry's weight and strength attributes (Safinia and Alkalbani 2016). Mokhtar et al. used plastic bottles as a wall structure for greenhouses to reduce $\mathrm{CO}_{2}$ emissions into the atmosphere. Sand was filled in discarded plastic bottles and compressed with a tamping rod in the investigation. The plastic brick had 
a maximum compressive strength of $38.34 \mathrm{~N} / \mathrm{mm}^{2}$, which was nearly 3-4 times higher than that of the normal clay brick (maximum of $8.58 \mathrm{~N} / \mathrm{mm}^{2}$ ). The comparison of the indoor and outdoor wall temperatures, air humidity and wind velocity of the plastic bottle greenhouse and the normal brick house showed that the plastic bottle had the highest outdoor wall temperature of $36{ }^{\circ} \mathrm{C}$ and the lowest outdoor humidity and wind velocity, respectively, of $78 \%$ and $0.8 \mathrm{~m} / \mathrm{s}$ (Mokhtar et al. 2016).

Various studies reported the use of HDPE and PET polymeric waste to increase the efficiency of unfired clay bricks. Three separate grain size additives (between 1 and $3 \mathrm{~mm}$ and 3 and $6 \mathrm{~mm}$ ) were examined at percentage of $0,1,3,7$, 15 and $20 \%$ by weight. The efficiency of the brick sample improved with the smallest polymeric grain additive of size $1 \mathrm{~mm}$. The bulk density of the bricks was less than $1.75 \mathrm{~g} /$ $\mathrm{cm}^{3}$, which indicates that the bricks were lightweight. The water absorption coefficient increased by nearly $17 \%$, and the compressive strength increased by $28 \%$ (Limami et al. 2020a, 2020b).

Water sachets made of LDPE can make LDPE sand bricks. The water sachets were first melted and then mixed with sand. Density, compressive strength and water adsorption of the bricks were dependent on sand particle size and sand to plastic ratio. The flexural strength and thermal conductivity of the best samples were measured. When processed under ideal processing conditions, LDPE-bonded sand proved to be a solid, durable material with compressive strength up to $27 \mathrm{MPa}$. They found the thermal conductivity at about $1.72 \mathrm{~W} / \mathrm{mK}$. In the bricks, the thermal diffusivity and specific heat values were $0.86 \mathrm{~mm}^{2} / \mathrm{s}$ and $2.0 \mathrm{MJ} / \mathrm{m}^{3} \mathrm{k}$, respectively (Kumi-Larbi et al. 2018).

According to a report, plastic waste and manufacturing sand were combined to make plastic-manufacturing sand (M sand) bricks. Based on trial and error, they used waste plastic and $M$ sand in the ratio of 1:1 and 1:2. To ensure the performance, strength and durability, the authors checked bricks for compression, water absorption, soundness and hardness tests. Plastic-M sand (ratio 1:2) bricks had the maximum compressive strength of $55.91 \mathrm{MPa}$, which was higher than that of regular bricks by $88.59 \%$ and $18.7 \%$ higher than bricks made from (1:1) plastic-M sand. Water absorption percentages for plastic-M sand ratio (1:1), for plastic-M sand ratio (1:2) and for regular bricks were $0.452 \%, 4.16 \%$ and $19.8 \%$, respectively (Leela Bharathi et al. 2020). Pavement bricks have also been reported by using polypropylene, manufacturing sand ( $M$ sand), river sand and ash. Three samples of bricks containing plastic and $\mathrm{M}$ sand $(20 \%$ and $80 \%$ ), plastic and river sand (25\% and $75 \%$ ) and plastic and ash $(30 \% \& 70 \%)$ were reported. Sample made up of waste plastic and fly ash had the highest compressive strength of $22.85 \mathrm{MPa}$ and the highest hardness of 6.087 (BHN or Brinell hardness number). Up to $80^{\circ} \mathrm{C}$, the bricks didn't degenerate. While checking efflorescence, a white patch was observed on the surface of the bricks. Results showed that plastic and ash-containing bricks were the most successful combination (Velmurugan 2019).

Polyethylene terephthalate (PET) and polyurethane (PU) binder was used to replace clay and cement in the production of interlocking bricks. The plastic bottles were finely chopped and grated to a size of $0.75 \mathrm{~mm}$ before combining with polyurethane (PU) and polymer. The mixer was placed in the interlocking brick machine mould and condensed. Using PET/PU in the ratio 60:40, the highest compressive strength achieved was $84.54 \%$ (lower than the control group), the highest tensile strength was $1.3 \mathrm{MPa}$, and maximum impact value was $23.343 \mathrm{~J} / \mathrm{m}$. The thermal conductivity was between 0.15 and $0.3 \mathrm{~W} / \mathrm{m} \mathrm{K}$. These bricks were suggested for use as a partition wall and found to be suitable as non-load-bearing masonry bricks (Alaloul et al. 2020). A moulded composite material was created by combining used PET from a municipal solid waste (MSW) landfill with fly ash. The fly ash percentage ranged from 0 to $50 \%$ by weight. The end products were examined for compressive strength, water absorption and density. It was found that fly ash lowers the thermal decomposition of PET, accelerates melting and mixing of PET and hampers shrinkage of the material during the moulding process. Scanning electron microscopy (SEM) and X-ray diffraction (XRD) studies were used to investigate the microstructure and bonding mechanism. According to XRD results, PET and fly ash bonded physically without any chemical reaction. The material's microstructure, as seen in the SEM micrographs, showed that the fly ash particles were homogeneously encapsulated in PET mass, resulting in a smooth surface of the composite material. The compressive strength was found to increase from 61 to $93 \mathrm{MPa}$ as with the increase in fly ash content from 0 to $50 \%$. The ductility of the composite material also increased with the increase in fly ash content. Furthermore, raising the amount of fly ash from 0 to $50 \%$ decreased linear shrinkage by a factor of 7 , from 3.9 to $0.54 \%$. The addition of fly ash to PET enhanced melting and mixing, while inhibiting thermal decomposition of PET. The water absorption value of composite material was very small (Li et al. 1998). Polyethylene terephthalate (PET), polypropylene (PP) waste, soil quarry waste and bitumen were employed in the manufacturing of bricks. Plastic waste from 65 to $80 \%$ and bitumen from 2 to $5 \%$ were employed in the production method. Plastic has sensible resistant properties. It is resistant to ozone, UV radiations and acid-alkali attack. Bitumen enhanced the binding property of plastic. With $5 \%$ bitumen and $70 \%$ plastic content, the maximum compressive strength was $10 \mathrm{~N} / \mathrm{mm}^{2}$. Maximum water absorption value was $1.8242 \%$ with $2 \%$ of bitumen and $45 \%$ plastic waste. Higher compressive strength was reported with PP as compared to PET (Puttaraj et al. 2018). PET waste in varied percentage of $0.5 \%, 1 \%, 1.5 \%$, 
$2 \%$, cement (7.5\%), fly ash (30\%) and quarry dirt (62.5\%) were used for manufacturing bricks. Four different samples with varied percentage of PET waste were created and cured for 7, 14 and 28 days for performing tests. Compressive strength, water absorption, bulk density, modulus of rupture and impact tests were performed, and the results were compared with ash bricks and clay bricks. PET bricks were less porous, uniform in form having rough surface and lighter have higher compressive strength and higher water absorption capability than the fly ash and clay bricks. Sample with $1 \%$ PET content gave highest compressive strength of $18.56 \mathrm{~N} / \mathrm{mm}^{2}$ and lowest bulk density, whereas sample with $0.5 \%$ waste gave highest modulus of rupture of $5.57 \mathrm{~N} / \mathrm{mm}$ after 28 days of curing. Sample with $2 \%$ waste has maximum impact value of 2.333 after 7 days of curing. Water absorption value was maximum, i.e. $11.5 \%$ for sample having $1.5 \%$ waste after 7 days of curing (Suganya 2015). PET bottles and sand were utilized in the manufacturing of bricks in the ratio 1:2, 1:3 and 1:4 which gives maximum water absorption value of $4.72 \%$ for $1: 4$ plastic-sand ratio and maximum compressive strength of $8.06 \mathrm{~N} / \mathrm{mm}^{2}$ for $1: 3$ plastic-sand ratio. Efflorescence test results were null. However, the sole drawback with these plastic sand bricks was that they ignite pronto (Selvamani et al. 2019). Polyethylene terephthalate (PET) mixed with lateritic clay at an increment of 5\% up to $20 \%$ for making fired bricks results in maximum compressive strength of $5.15 \mathrm{~N} / \mathrm{mm}^{2}$ and maximum modulus of rupture value of $13.20 \mathrm{~N} / \mathrm{mm}^{2}$ with $0 \%$ plastic waste which showed that with addition of waste, both compressive strength and modulus of rupture decreased. Water absorption value bated from 10.29 to $6.57 \%$ on addition of plastic waste (Akinyele et al. 2020).

Waste thermoplastics, such as polycarbonates (PC), polystyrenes (PS), mixed plastic, as well as sand, ash and regular Portland cement in varying proportions, were used in the construction of bricks. The proportion of thermoplastic was $0-10 \%$ by weight, sand was $60-70 \%$ by weight, and the proportion of fly ash and Portland cement was $15 \%$. Resulting bricks were porous, lightweight and thermal resistant and have compressive strength over $17 \mathrm{MPa}$ and maximum water absorption value of $14.18 \%$, and bulk density decreased from 2.06 to $1.60 \mathrm{~g} / \mathrm{cm}^{3}$ on addition of waste (Mondal et al. 2019). Rice husks and waste expanded polystyrene along with styrene as a binder in different mix proportions were used to prepare rice husks-plastic building composites using a hot press moulding process. These composites were tested for apparent density, water absorption, thickness expansion and dry and wet flexural forces. The apparent density of the composites was between 0.80 and $1.60 \mathrm{~g} / \mathrm{cm}^{3}$. Regardless of the filler-binder ratio, the water absorption of the composites reduced with an increase in binder content. The dry and wet flexural strength of the composites improved with an improvement in the filler-binder ratio, reaching the maximum value at a binder content of $30 \%$ (Choi et al. 2006). However, bricks made from waste plastics like polyethylene, high-density compound (nylon 66) and polythene terephthalate along with red soil, river sand and stone crush in numerous compositions showed $0 \%$ water absorption value for plastic bricks and maximum compressive strength of $15.50 \mathrm{kN}$ when river sand was used with plastic waste. No sound was detected throughout the soundness test, and these bricks were hard and durable (Kognole et al. 2019).

Nowadays ash from thermal power plants is also used for bricks and other construction material. Taking the advantage of ash bricks, researches are examining its combination with waste plastic as well. In bricks, LDPE can be mixed with materials such as bottom ash, copper slag and ceramic in various quantities. In rough weather conditions, LDPE and bottom Ash mixed in ratio (3:1) yields the maximum compressive strength of around $16 \mathrm{MPa}$ and $4.2 \%$ water absorption, satisfying all standard specifications except the ASTM average. LDPE mixed with ceramic aggregates in ratio (3:1) and $10 \%$ oil yields the maximum compressive strength of around $22 \mathrm{MPa}$ and water absorption value of $4.9 \%$, and any mix with ceramic aggregates had theoretically crossed $15 \mathrm{MPa}$ and had satisfied all normal specifications except ASTM norm in hard weather condition. The highest compressive strength of around $21.4 \mathrm{MPa}$ and water absorption value of $4.5 \%$ were obtained by mixing LDPE with copper slag in a 2:1 blend ratio in the presence of a coupling agent. Plastic and ceramic waste combined in a 3:1 ratio gave the best block (Monish et al. 2021). Also, various amounts of plastic trash (LDPE type) were mixed with granite dust, sand and clay to form paver blocks. The 50:50 mix ratio (plastic melt-granite dust) achieved the highest compressive strength of $15.0 \mathrm{~N} / \mathrm{mm}^{2}$, according to the compression test. The 70:30 mix ratio (sand-plastic melt) had the highest flexural strength of $14.28 \mathrm{kN}$, according to the flexural test results (Wahab Folorunsho et al. 2020).

A study reported composite bricks made up of powdered polythene waste mixed with fly ash and tested for soundness, hardness, water absorption ability and compressive strength. Composite bricks made a much clearer tone and were much more resilient than red and ash bricks. Water absorption capacity reduced from $0.8206 \%$ with no waste to $0.40043 \%$ with $100 \%$ polythene waste. The maximum wet and dry compressive strength with $10 \%$ polyethylene composite bricks was 20.34 MPa and 21.017 MPa. Results showed that these bricks were cost-effective and environmentally friendly (Sonone and Devalkar 2017). Another paper reported fly ash combined with recycled polymers in percentage of $0 \%, 25 \%, 50 \%$ and $75 \%$ by weight of fly ash. The properties of ash mixed with recycled plastics obtained from computers, TV sets, mobile phones, AC, table, chairs and electronic chip waste had been checked. Direct shear test, triaxial shear test and X-ray light test were performed 
on ash alone and ash mixed with recycled plastic polymers. The maximum dry density (MDD) was $1330 \mathrm{~kg} / \mathrm{m}^{3}$, and the maximum optimum moisture content (OMC) value was $30 \%$ with 50\% recycled plastic (Salunkhe and Mandal 2014).

Bricks and paver blocks made from plastic waste (HDPE and PE) and sand taken in ratio 1:2, 1:3, 1:4, 1:5 and 1:6 were reported and evaluated for compressive strength, water absorption, efflorescence, hardness and fireplace resistance. A comparative study of ash bricks, plastic sand bricks, and traditional bricks showed that plastic sand bricks have highest compressive strength of $5.12 \mathrm{~N} / \mathrm{mm}^{2}$ out of these bricks and paver blocks have compressive strength $9.19 \mathrm{~N} / \mathrm{mm}^{2}$. The water absorption capability of plastic sand bricks was $1.10 \%$, and that of plastic paver blocks was $1.082 \%$. Structural property of bricks and blocks didn't show significant changes up to $180^{\circ} \mathrm{C}$. All these results showed that the plastic sand bricks and paver blocks were of better quality than ash bricks and traditional clay bricks (Sellakutty et al. 2016). Waste plastic obtained from potable bottles (PET), carry bags, bottles caps, household articles (HDPE), milk pouches, sacks, carry bags, bin linings, cosmetics and detergent bottles (LDPE), etc. can also be used for making bricks. All the plastic waste was pulverized, heated in a chamber, mixed with stone dirt and moulded to make bricks and tiles. Absorption test, form and size test, soundness test, hardness test, efflorescence test and compressive strength tests were performed on the plastic bricks. The authors found that the values for water absorption and efflorescence tests were nil. Plastic sand bricks were heavy with a scratch on the surface with a compressive strength of $5.6 \mathrm{~N} / \mathrm{mm}^{2}$ (Singhal and Omprakash Netula 2018). Apart from the mixture of waste plastic, the dust obtained from PVC pipes was employed in the manufacturing of bricks by using plastic extruder machine. These bricks were then compared with burnt clay bricks. Plastic dust bricks were lighter with compressive strength of $6.66 \mathrm{~N} / \mathrm{mm}^{2}$ which was more than that of clay bricks having compressive strength $3-5 \mathrm{~N} / \mathrm{mm}^{2}$ (Shah et al. 2017). High-density polyethylene (HDPE) in different percentages as $2.5 \%, 3.0 \%$ and $3.5 \%$ was used in construction bricks. Compressive strength and the initial water absorption tests were performed on the bricks on the 7th and 28th day. On the 28th day, samples containing 3.0\% HDPE had the highest compressive strength of $15.9 \mathrm{~N} / \mathrm{mm}^{2}$ as compared to samples containing $2.5 \%$ and $3.5 \%$ HDPE. The initial water absorption rate was recorded as $2.35 \mathrm{~kg} / \mathrm{m}^{2}$ min for $3.5 \%$ HDPE replacement (Ali et al. 2017). In this study, earth clay was mixed with various amounts of high-density polyethylene (HDPE) and polyethylene terephthalate (PET) additives with three different grain sizes. Thermal conductivity, specific heat capacity, time lag and decrement factor properties were investigated on the prepared samples. In comparison to control samples having thermal conductivity $0.48 \mathrm{~W} / \mathrm{m}$ $\mathrm{K}$, the thermal conductivity for large polymeric additions reached $0.18 \mathrm{~W} / \mathrm{m} \mathrm{K}$ and $0.20 \mathrm{~W} / \mathrm{m} \mathrm{K}$ for PET- and HDPEbased samples, respectively, suggesting a $63 \%$ and $58 \%$ increase in thermal conductivity. When compared to control specimens, the gain percentage for specific heat capacity was in the range of $85 \%$ and $79 \%$ for PET and HDPE additive brick samples, respectively. In fact, the reported time lag and decrement factor for a 0.3 -m-thick external wall made of PET-based samples were $13.50 \mathrm{~h}$ and 0.148 , respectively, compared to $8.99 \mathrm{~h}$ and 0.346 for reference values (Limami et al. 2020a, 2020b).

Besides bricks and paver blocks, plastic waste has also been employed for making different tiles. Roof tiles using recycled high-density polythene (HDPEr) and sand were reported. The percentage of HDPEr in the mixture varied from 30 to $80 \%$ by weight. Density test, flexural breaking load test and impermeability test were performed on the tiles. The results revealed that as the percentage of plastic waste increased, the density of tiles decreased from 1.8 to $1.379 \mathrm{~kg} / \mathrm{m}^{3}$, impermeability decreased, but flexural strength increased (Seghiri et al. 2017). Usage of waste plastic and broken glass was also reported for roof tiles, hollow blocks and floor tiles. In these, plastic waste replaced cement and broken glass replaced river sand partially. For hollow blocks, the proportion of plastic waste, fine glass and fine sand was $33 \%, 11.2 \%$ and $44.6 \%$, respectively. For roof tiles, $30 \%$ plastic waste and $70 \%$ glass were used, and for floor tiles, $32 \%$ plastic and $68 \%$ glass were used. The optimum compressive strength got was $27 \mathrm{MPa}$. For roof tiles, the average breaking strength was measured to be $2356 \mathrm{~N}$ (Behera 2018).

Polythene luggage and demolition waste in place of cement were used to produce paver blocks. They made three distinct samples using plastic and sand in the ratios of 1:2, $1: 3$ and $1: 4$. River sediment made up $0.75 \%$ of the sand mix, while demolition waste made up $0.25 \%$. The investigators checked paver blocks for compressive strength, flexural strength, tensile strength, water absorption, efflorescence, toughness, fire resistance, free thaw resilience and SEM study. After extensive research, it was determined that paver blocks with a quantitative relationship of $1: 3$ have the best outcomes. Sample 2 had a maximum compressive strength of $7.74 \mathrm{~N} / \mathrm{mm}^{2}$, a maximum flexural strength of $1.17 \mathrm{~N} / \mathrm{mm}^{2}$ and maximum tensile break strength of $5.21 \mathrm{~N} / \mathrm{mm}^{2}$. Sample 2 showed the lowest water absorption ratio, $1.33 \%$. Since the plastic content of sample 1 is high, the scratch is simply rendered on the paver block's surface. Because of the weak bonding in sample 3, sand separates from the paver block's base, making it less durable (Hemalatha 2019). Another report suggested the use of melted waste plastic bags as a cement substitute in the manufacturing of building bricks and concrete blocks. Thermal conductivity of the bricks reduced from $1.70 \times 10^{-3} \mathrm{~W} / \mathrm{m} \mathrm{K}$ to $1.43 \times 10^{-3} \mathrm{~W} / \mathrm{m} \mathrm{K}$ with the increment in plastic content from 33.33 to $66.67 \%$. While 
increasing the plastic content in concrete blocks from 20 to $50 \%$, the thermal conductivity fell from $1.61 \times 10^{-3} \mathrm{~W} / \mathrm{m} \mathrm{K}$ to $1.50 \times 10^{-3} \mathrm{~W} / \mathrm{m} \mathrm{K}$. (7). The authors had observed that the variation of thermal conductivity with plastic content (50\%) is similar in bricks and concrete blocks. The bending moment, hence the bending stress, increased with increase in plastic content for both the bricks and concrete. Increasing the brick's plastic content from 33.33 to $66.67 \%$ resulted in an increase in the bending moment from 540.00 to $1711.25 \mathrm{~N} \mathrm{~m}$ and the bending stress from 3.24 to $10.26 \mathrm{~N}$ $\mathrm{m}^{2}$. Because of its lightweight, high adaptability and ability to be changed to fit specific technological needs, waste plastic can be made as construction materials such as bricks and concrete blocks (Abdel Tawab et al. 2020).

All the above-mentioned significant results are tabulated in Table 1, to analyse the optimum mechanical properties of different compositions of waste plastics in the manufacturing of bricks, tiles and blocks.

\section{Utilization of plastic waste in concrete/road construction}

For road construction, the improvisation of concrete using plastic is already in practice in different parts of the world. Researchers have investigated different admixtures of plastics as a partial or total replacement of aggregate.

A study reported recycled plastic-bounded concretes (RPBCs) made from $100 \%$ waste plastic and no asphalt binder or Portland cement. They investigated mechanical properties, crack recovery and thermal and moisture sensitivity of recycled plastic bounded concrete. Two types of recycled plastic waste, recycled high-density polyethylene (rHDPE) and recycled polypropylene (rPP), were used. The compressive strength of recycled polypropylene-bounded concrete was $30 \mathrm{MPa}$, which was almost three times that of asphalt binder concrete. Recycled PP had three times the bending strength of plain cement concrete (PCC) and five times the bending strength of asphalt concrete (ACs). The crack healing performance of RPBCs was approximately 92\%. RPBC showed greater resistance to moisture exposure. The strength of recycled PP was reduced by $5 \%$, while the strength of asphalt concrete was reduced by $17 \%$. The bending power of ACs was just up to $10 \%$, but the strength of recycled HDPE- and recycled PP-bounded concrete was 85 and $99 \%$, respectively. Because of its failure to confine the aggregates in concrete, the authors inferred that recycled HDPE was not as effective as recycled PP. Since cement production releases an extensive amount of $\mathrm{CO}_{2}$ and requires a sizeable amount of oil, substituting waste plastic for cement was environmentally friendly (Dalhat and Al-Abdul Wahhab 2016).
In some reports, PET derived from drinking water bottles was used as a replacement of sand in concrete formation. Different volumetric percentages of sand, such as $2 \%, 5 \%$, $10 \%, 15 \%, 20 \%, 30 \%, 50 \%, 70 \%$ and $100 \%$, were substituted by the same volumetric percentage of recycled PET aggregate. When the volume of aggregate was between 0 and $30 \%$, the bulk density remains small. However, as the volume approaches $50 \%$, the bulk density decreased and showed a minimum value of $1000 \mathrm{~kg} / \mathrm{m}^{3}$. In addition, by increasing the amount of aggregate from 0 to $50 \%$, the compressive power reduced by $15.7 \%$ as compared to the reference mortar. However, compressive strength greater than 3.5 MPa was observed when the volume of sand was fully replaced by PET. Up to a replacement stage of 50\%, high compactness was found. Beyond 50\% volume, the arrangement seems to be more spacious/broad (Marzouk et al. 2007). The mechanical properties of concrete with polyethylene terephthalate fibres (PET) of length 10, 15 and $20 \mathrm{~mm}$ and volume in percentages of $0 \%, 0.05 \%, 0.18 \%$ and $0.30 \%$ were investigated. With PET fibres, the slump value of concrete decreased from 100 to $50 \mathrm{~mm}$. After 28 days, the maximum flexural intensity was $4.47 \mathrm{MPa}$, and after 150 days, it was $4.48 \mathrm{MPa}$ with $0.30 \%$ fibre volume. With $0.30 \%$ fibre volume, the maximum compressive intensity was $29.52 \mathrm{MPa}$ after 28 days and $29.69 \mathrm{MPa}$ after 150 days. After 150 days of curing, the highest modulus of elasticity was 27.31 GPa (Pelisser et al. 2012). A report suggested concrete made from recycled PET flake aggregates. PET was used in percentages of $1,3,5,7$ and $10 \%$ by weight of Portland cement. The maximum compressive strength with $1 \%$ PET was $20.720 \mathrm{MPa}$, and the flexural strength increased to $23.11 \%$ and $25.59 \%$ in comparison to the concrete without waste. The density of concrete declined from 2.276 to $2.15 \mathrm{~g} / \mathrm{cm}^{3}$ as the percentage of PET increased from 1 to $10 \%$. Splitting tensile strength improved, especially at $1 \%$ and $7 \%$ PET, with increment ratios of $130 \%$ and $102 \%$, respectively, as compared to the reference concrete (Hameed and Fatah Ahmed 2019). Similarly, waste PET was used as a plastic aggregate in concrete. Waste plastic replaced conventional coarse aggregates in the quantity of 5\%,10\% and $20 \%$ by volume. Concrete samples with plastic waste were then compared with concrete without plastic waste. Compressive strength, tensile strength, modulus of elasticity, flexural strength and shrinkage test were performed according to ASTM C39, ASTM C496, ASTM C469, ASTM C78 and IS:1199-1959 standards. Investigators observed that the density of concrete decreased on addition of plastic waste. Concrete specimen containing $10 \%$ of waste PET showed higher values of compressive strength and modulus of elasticity as compared to other specimens. The flexural strength of concrete declined on the addition of waste plastic. Water absorption was found maximum in concrete containing $20 \%$ plastic by volume (Hossain et al. 2016). To overcome the 


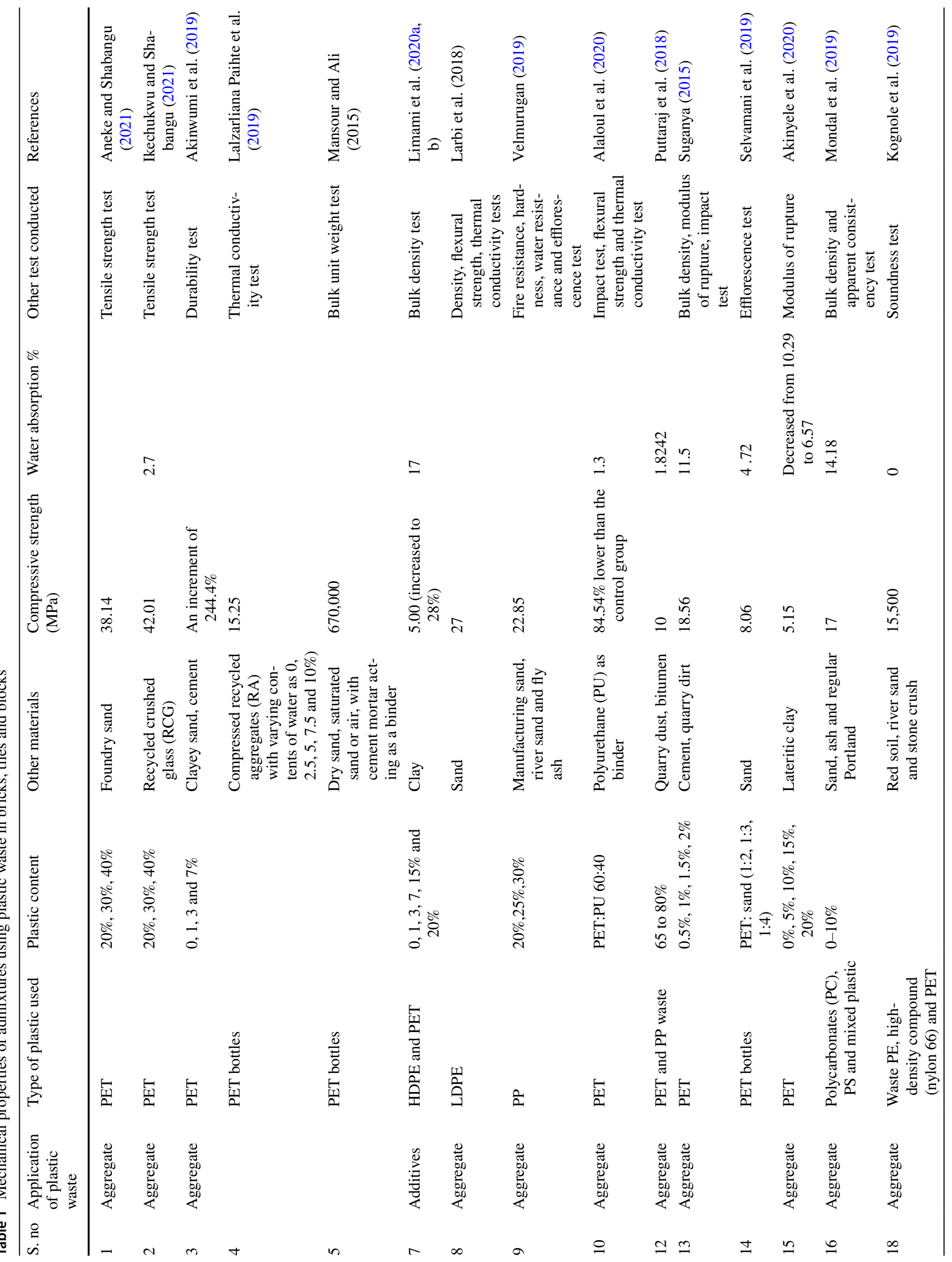




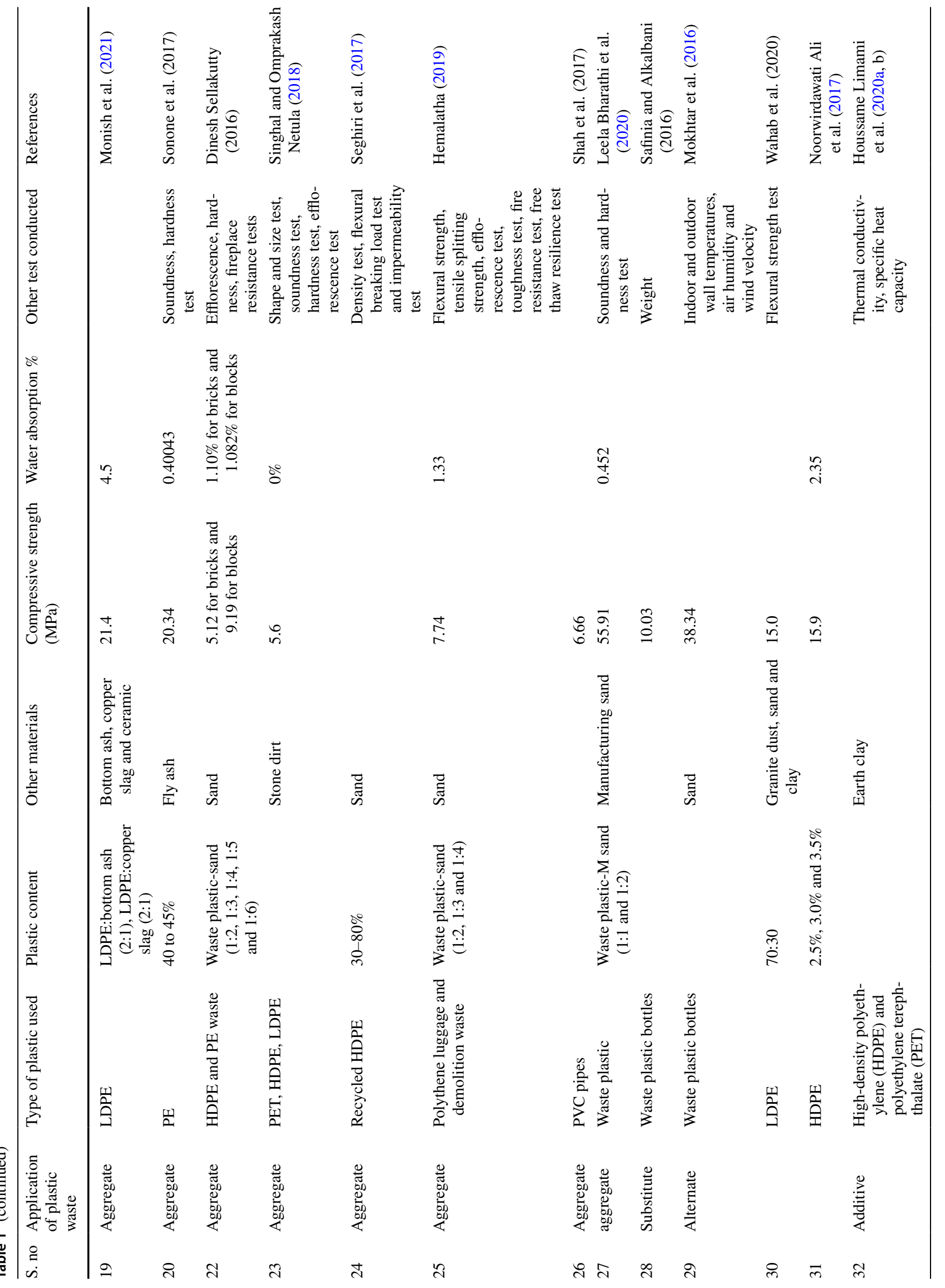


environmental effects of PET disposal, PET waste was investigated as a replacement of aggregate in asphalt concrete mixes (PlastiPhalt). Four different volume percentages of plastic $(0 \%, 10 \%, 20 \%, 30 \%, 40 \%, 50 \%)$ were used to make total forty-eight specimens, and six beams and cylinders each for M20 grade of concrete were prepared.

Concrete containing synthetic aggregates (SA) was investigated for toughness properties. SA replaced natural pumice lightweight coarse aggregate or Lytag aggregate in $25 \%, 50 \%, 75 \%$ and $100 \%$ by volume of concrete. Split tensile strength decreased as the percentage of plastic waste increased. It was because of the weak bonding between plastic aggregate and cement paste, which reduces the resilience of the concrete mixture to loads. When compared to the control mixes, the synthetic aggregate concrete (SAC) was less consistent. The slump of SAC mixes was 11-23\% lower than lightweight aggregate and $31 \%$ lower than Lytag aggregate. As the percentage of aggregate increased from 50 to $100 \%$, the drying shrinkage of the SAC mixes increased by $19-54 \%$ after 182 days of curing. After 28 days of curing, the water absorption and chloride permeability of SAC mixes decreased by 5-20\% and 9-17\%, respectively, as the substitution amount of PA with SA increased from 25 to $100 \%$. The reduction in water absorption and chloride permeability for SAC with $100 \%$ substitution of Lytag aggregate (LA) was $23 \%$ and $18 \%$, respectively (Alqahtani et al. 2018). In another study on lightweight concrete, thermosetting plastic was used as an admixture in the blend design and tested for dry density and compressive strength. In this work, different proportions of plastic, sand, water-cement ratio, aluminium powder and lignite fly ash were used. The experimental findings showed that the use of plastic resulted in decreased dry density and less power. It was observed that the mix proportion of 1.0:0.8:0.3:0.9 of clay, sand, fly ash and plastic, respectively, was an acceptable mix proportion (Panyakapo and Panyakapo 2008). A study reported that devulcanized synthetic resin terephthalate would improve the performance and properties of modified asphalt binders. Penetration, softening point, storage stability and dynamic shear rheometer tests were performed to investigate the behaviour of four binder samples. As compared to base asphalt binder, the compound showed less penetration and enhanced softening point, viscosity and permanent deformation resistance of modified binders. Storage stability testing revealed that each compound alteration would not satisfy the Superpave binder standard limit and would not be a storage stable combination. The rutting parameter and high failure temperature values of all three polymers were increased (Ameri and Nasr 2016).

In M20 grade paver and solid blocks, waste plastic from 0 to $10 \%$ (in an increment of $2 \%$ ) was used to replace the same amount of aggregate. Compressive strength analysis for 7, 14 and 28 days revealed that the maximum 
compressive strength was $26.4 \mathrm{~N} / \mathrm{mm}^{2}$ for paver blocks and $23 \mathrm{~N} / \mathrm{mm}^{2}$ for solid blocks with $2 \%$ waste plastic. The optimum modifier percentage was $4 \%$ for paver blocks and $2 \%$ for solid blocks (Vanitha et al. 2015).

Stabilized stone mastic asphalt (SMA) mixtures were compared to the conventional mix (without plastic). The mixtures underwent tests for Marshall stability, tensile strength, compressive strength and triaxial test. An addition of $10 \%$ plastic content resulted in an increase in the stability, split tensile strength and compressive strength of about $64 \%, 18 \%$ and $75 \%$, respectively, compared to the conventional SMA mix. The Marshall stability value of stabilized SMA was $16.83 \mathrm{kN}$ with a comparative increase of $64 \%$. Compressive strength of stabilized mix increased by $14 \%$. Triaxial test results exhibited an increase of $44 \%$ in cohesion. Angle of shearing resistance showed a decrease of $29 \%$ indicating an increase in the shear strength (Bindu and Beena 2010).

Researchers reported manufacturing of lightweight and ductile concrete by partial replacement of river sand with PVC pipe waste granules in percentages of 5\%, 15\%, 30\% and $45 \%$ by volume. Resulting concrete showed higher Poisson's ratio and decreased modulus of elasticity. It also possessed greater resistance to chloride ion penetration and less shrinkage on drying. The drying shrinkage further reduced with an increase in the quantity of waste plastic. However, high amounts of plastic waste also led to a reduction in workability, compressive strength and tensile splitting strength of the concretes (Kou et al. 2009). Another report on the utilization of PVC powder and granules in concrete showed normal to high strength concretes by using $10 \%$, $20 \%$ and $30 \%$ replacement ratios of PVC powder and granules by volume of aggregate. Then, physical and mechanical properties of polyvinyl chloride (PVC)-containing concretes were observed. The compressive strength and capillary water absorption values of the modified concrete are lower than that of the reference mixtures. Limit of abrasion resistance decreased with the increase in percentage of PVC powder and granules (Bolat and Erkus 2016).

Haghighatnejad et al. studied the effect of curing condition on the compressive strength, splitting tensile strength, elastic modulus and initial and final absorption of concrete containing natural sand aggregate and concrete with recycled PVC (RPVC) aggregate. Results showed that irrespective of the curing condition, RPVC reduces the mechanical properties of concrete measured in terms of compressive strength, splitting tensile strength and modulus of elasticity. Curing condition affects the strength of both natural and RPVC aggregate concretes; however, the RPVC aggregate concrete is more sensitive to air storage curing. Splitting tensile strength and modulus of elasticity of mixtures decreased up to $23.4 \%$ with an increase in the RPVC aggregate content after 28 curing days. Use of RPVC aggregate reduced the slump value of normal concrete up to $48 \%$ due to its sharp edges (Haghighatnejad et al. 2016).

Dombe et al. prepared bituminous mixtures made of E-waste and plastic waste. Waste plastic substituted bitumen by 4.5 to $6 \%$ of the total amount of bitumen used. Shredded electronic waste partially substituted aggregates ( $7.5 \%, 10 \%, 12.5 \%$ and $15 \%$ by volume of the mould). Plastic raises the melting point of bitumen, allowing the asphalt to remain flexible throughout the winter, and shredded plastic waste helps to keep the road in good condition. The penetration value of bitumen declined by $6.68 \%$ after mixing $6.5 \%$ waste plastic in it, but the softening point of bitumen improved by $8.60 \%$ The other properties of bitumen remained the same. Upon coating $7 \%$ of waste plastic on aggregate, the specific gravity increased by $2.88 \%$, while the crushing value, effect value and loss abrasion value decreased by 3 to $4 \%$ (Dombe et al. 2020). Similarly, electronic plastic waste was used in concrete by replacing aggregates from 0 to $20 \%$ on strength criteria of M20 grade. Optimum values of hardness and durability of concrete were obtained by addition of $10 \%$ E-plastic content in cement. Compressive strength decreased from 18.55 to $10.72 \mathrm{~N} / \mathrm{mm}^{2}$ on adding waste from 0 to $20 \%$ on 28 days of testing. Flexural strength decreased from 3.14 to $2.74 \mathrm{~N} / \mathrm{mm}^{2}$, and split tensile strength decreased from 2.137 to $1.91 \mathrm{~N} / \mathrm{mm}^{2}$. Authors suggested that utilization of E-plastic in concrete will reduce the requirement for conventional fine aggregates resulting in conservation of natural resources (Gavhane et al. 2016). It was also found that E-waste from 0 to $21.5 \%$ (i.e. $7.5 \%, 14 \%$ and $21.5 \%)$ on strength criteria of M30 concrete reduces the compressive strength by $52.98 \%$ when fine aggregates were replaced by $21.5 \%$ E-waste (Damal et al. 2015). Another paper reported that by using $30 \%$ of E-waste, the slump value of concrete decreased from 128 (control) to $75 \mathrm{~mm}$ (30\% E-waste) and compressive strength decreased from 47.18 to $22.15 \mathrm{~N} / \mathrm{mm}^{2}$ after 28 days of curing. Split tensile strength decreased from 4.9 to $3.8 \mathrm{~N} / \mathrm{mm}^{2}$, and flexural strength decreased from 4.35 to $2.5 \mathrm{~N} / \mathrm{mm}^{2}$ on addition of waste plastic after 28 days of curing (Manjunath 2016). Another researcher examined plastic waste as a replacement to natural aggregate in concrete. They casted 60 cubes, 60 cylinders and 40 prisms to identify the compressive strength, split tensile strength and flexural strength. Fine aggregates were replaced with plastic fine (PF) aggregate measured as $10 \%, 15 \%$ and $20 \%$ by weight, and coarse aggregates were replaced with corresponding $15 \%, 20 \%$ and $25 \%$ plastic coarse (PC) aggregate. In addition, $0.3 \%$ of steel fibre was added by weight of cement. The compressive strength of concrete decreased from 9 to $17 \%$ on adding waste plastic. It was attributed to poor bonding between concrete and plastic aggregates. Split tensile strength decreased from 10 to $24 \%$ and flexural 
strength reduced in the range 20 to $30 \%$ (Jaivignesh and Sofi 2017). In a report, researchers utilized processed tenuity polythene (LDPE) plastic in share from 1 to $5 \%$ for the preparation of bituminous mix. Use of polyethylene waste in bituminous mix reduces porousness; however, absorption of wetness increases the binding property. The Marshall stability test exhibited value of $17.7 \mathrm{~kg}$ on the addition of $4 \%$ plastic waste, and the Marshall flow value weakened from 2.31 to $2.18 \mathrm{~mm}$ on addition of waste from 0 to $5 \%$. The results obtained on using $4 \%$ polyethylene waste showed higher performance than alternative mixes of waste (Soyal 2015). Concrete incorporated with quarry dust and plastic waste was examined for strength properties. Quarry dust and waste plastic (LDPE) in fibre form were added as $0 \%, 25 \%, 50 \%, 75 \%$ and $100 \%$, respectively, to replace natural sand. Particle size distribution was studied by X-ray diffractometry (XRD) and scanning electron microscopy (SEM) techniques. SEM results showed that quarry dust particles are fine in nature with average size of 2 to $3 \mu \mathrm{m}$, and LDPE images show that it is having lamellar, crystalline (fibre like) structure. It is not having porous structure but its lamellar structure increases the strength carrying capacity. Digital microscopy showed that conventional concrete mixes were more porous leading to matrix cracking, but the mixture of quarry dust-waste plastic substitution resulted in refined matrix densification (Bahoria et al. 2017).

Waste plastic like polyethylene and polystyrene in sliced form was coated over aggregates and mixed with hot bitumen. Various tests like crushing strength test, abrasion test, Los Angeles abrasion test, impact test, softening point test and surface test were performed on traditional aggregates and plastic-coated aggregates. Crushing value decreased from 23.22 to $14.22 \%$ on adding plastic waste. The softening point was $81.2{ }^{\circ} \mathrm{C}$ and penetration value was $67 \mathrm{~mm}$. The loss angle abrasion value reduced from 5.6 to $4.2 \%$ of plastic-coated hydrocarbon (Manju R et al. 2017).Various varieties of plastics like thermosets, elastomers and thermoplastics reported to increase the temperature of the bitumen, hence improving the road life. Waste plastic coating over mixture enhanced the compressive strength to $320 \mathrm{MPa}$ and bending strength to $390 \mathrm{MPa}$ by exploitation of $40 \%$ waste plastic (Rokdey et al. 2015).

A recent communication reported high-strength lightweight concrete employing recycled high-impact polystyrene (HIPS) and low-density polyethylene (LDPE) plastic wastes. Plastic granules with particle sizes of about $2 \mathrm{~mm}$ were obtained by recycling HIPS and LDPE plastic wastes. These plastic wastes partially replaced sand at various percentage levels of $0,10,30$ and $50 \%$ by weight in concrete mixes. Investigators casted $100 \mathrm{~mm}$ concrete cube samples and examined both the fresh and hardened states. As the quantity of recycled waste plastic granules increased, test results showed a reduction in workability, density and compressive strength. After 28 days of curing, the concrete mixtures having $10 \%$ recycled plastics were able to meet the goal strength of $30 \mathrm{~N} / \mathrm{mm}^{2}$ (Olofinnade et al. 2021).

Basha et al. reported recycled waste plastic as a substitute of natural aggregates. They prepared eighteen concrete compositions with varied recycled plastic aggregate (RPA) proportions $(25,50,75$ and $100 \%)$ and two cement contents $\left(350,370 \mathrm{~kg} / \mathrm{m}^{3}\right)$ having water to cement ratios of 0.45 and 0.4 and assessed their mechanical and thermal properties. To create lightweight concrete with a unit weight of $1500 \mathrm{~kg} /$ $\mathrm{m}^{3}$ and a compressive strength of $17 \mathrm{MPa}, 100 \%$ recycled plastic aggregate (RPA) was used. The maximum compressive strength of $35 \mathrm{MPa}$ was observed with $25 \% \mathrm{RPA}$. The control concrete had a thermal conductivity of $1.7 \mathrm{~W} / \mathrm{m}$ $\mathrm{K}$, while the RPA concrete had a thermal conductivity of $1.1-0.5 \mathrm{~W} / \mathrm{mK}$. The flexural strength of concrete with a water/cement ratio of 0.4 and 0.45 was 4.9 to $2.6 \mathrm{MPa}$ and 4.5 to $2.6 \mathrm{MPa}$, respectively (Basha et al. 2020).

The waste plastic bottles, cups, caps, etc. were powdered or blended with crusher and coated over the aggregate and bitumen mixture by heating process for road construction. The aggregate of size $10-20 \mathrm{~mm}$ and $60 / 70$ and $80 / 100$ grade of bitumen was used. As the percentage of plastic increased, the softening point, flash point and fire point improved, whereas penetration value and ductility decreased. The polymer-coated aggregate and bitumen mixture showed higher strength, better binding property, stability, increase in wear resistance and better durability of roads (Chada Jithendra Sai Raja et al. 2020).

Recycled polypropylene (PP) plastic particles were used as a modifier in self-compacting lightweight concrete (SCLC). In the concrete, waste plastic replaced sand $(10 \%, 15 \%, 20 \%$ and $30 \%$ by volume). This paper reported a different trend in slump value, where increase in percentage substitution resulted in enhanced slump flow value of concrete. With a replacement of up to $15 \%$, passing ability improved, whereas the viscosity and elastic modulus of SCLC showed a reduction. The dry bulk density of concrete decreased up to $15 \%$ with $30 \%$ replacement level of sand. The compressive strength, splitting tensile strength and flexural tensile strength showed increase with the replacement level up to $15 \%$. Up to $20 \%$ replacement level, the compressive strength of SCLC was improved, but with $15 \%$ sand, the maximum compressive strength was obtained. The measurement of splitting tensile strengths and flexural tensile strength after 7 days and 28 days showed maximum value when the replacement level was $15 \%$. But beyond this percentage, the properties deteriorated due to the mismatch between the plastic and cement paste (Yang et al. 2015). Shredded plastic bags (SPB) in varying percentages $(0,0.5,1,2,3$ and $5 \%)$ by weight of concrete were used as concrete additive materials. The 
specimens were then examined for workability, density, compressive strength, flexural strength, water permeability, static and dynamic modulus of elasticity and abrasion resistance. The maximum compressive strength of 26.1 MPa and maximum flexural strength of $3.55 \mathrm{MPa}$ were observed with $0.5 \%$ waste plastic bags after 28 days of curing. Water penetration and abrasion resistance against rubbing and scraping effect of SPB increased with increase in plastic waste. However, mechanical properties of concrete degraded with increase in percentage of waste plastic. Poor bonding was observed between concrete and plastic matrix (Jain et al. 2019).

Waste polythene in the range of 5 to $11 \%$, when mixed with bitumen (60/70) grade, proved to be a good binding agent for the construction of road (Kazmi and Rao 2015). In a report, waste plastic collected from municipal solid waste was used as a coated mixture in bituminous construction. Marshall properties, impact values, abrasion, water absorption and soundness tests were performed on the plasticcoated aggregates. Maximum value of Marshall stability for plastic-coated mixture was found to be $2812.1 \mathrm{~kg}$ corresponding to $4.7 \%$ bitumen by weight. Plastic-coated mixture showed improved water absorption and soundness. Once used for construction, it will stand up to higher temperature (Dawale 2016). Waste plastic was also used as a modifier for quasi-dense bituminous concrete. Chopped plastic was mixed in hot mixture by using $6,8,10,12$ and $14 \%$ plastic by weight of hydrocarbon. Marshall stability value was maximum, i.e. $13.0 \mathrm{~kg}$ for $12 \%$ plastic by weight of the bitumen; however, for this \% of plastic, the soundness value has ablated. Maximum flow value was $4.0 \mathrm{~mm}$, and voids filled with bitumen (VFB) was $75.9 \%$ by adding $14 \%$ waste plastic (Rajput and Yadav 2016).

Azhdarpour et al. reported that the addition of plastic particles to freshly formed concrete impacted both physical and strength-related characteristics. Precisely, as the plastic fragment ratios increased, physical attributes (like density and ultra sound velocity) dropped significantly. When 5-10\% of the concrete fine particles were replaced with the same amount of polyethylene terephthalate (PET) fragments, the compressive, tensile and flexural strength of the samples increased. The study also indicated that substitution of more than $10 \%$ results in a significant decrease in all concrete strength-related measures. As a result, it was proposed that replacing fine particles with PET fragments may have a positive impact on the strength-related characteristics of concrete samples as long as the substitution ratio is less than $10 \%$. The addition of plastic to the concrete mixture decreased both the fresh and dry densities of the concrete, according to the results of fresh and dry density measurements. The samples containing $30 \%$ plastic particles experienced the greatest loss of density, which was equal to $9 \%$ (Azhdarpour et al. 2016).
Another study reported the influence of plastic as an alternative coarse aggregate on various fresh and harden properties of concrete. The thermoplastic polymer polyethylene terephthalate (PET) was regarded an alternative aggregate and was replaced with natural coarse aggregate, such as brick chips. PET aggregation was made by shredding, melting and crushing the PET bottles that have been collected. The authors compared the compressive strength, unit weight and workability of PET aggregate concrete (PAC) to that of natural aggregate concrete (NAC). In comparison to NAC, PAC has lower unit weights and compressive strength as the PET replacement ratio and $w / c$ ratio increase. At a $0.42 \mathrm{w} / \mathrm{c}$ ratio, the compressive strength of $20 \%$ PET-substituted PAC is $30.3 \mathrm{MPa}$, which is only $9 \%$ less than NAC. However, PAC has a strong workability, as seen by a $1.8 \mathrm{~cm}$ slump value when $20 \%$ PET was replaced with PAC at a $0.42 \mathrm{w} / \mathrm{c}$ ratio. As a result, structural concrete can be made from PETreplaced concrete with a low w/c ratio and great workability (Islam et al. 2016). Metalized plastic waste (MPW) such as polypropylene (PP) was used in concrete to check its workability and strength properties by evaluating slump, compressive and splitting tensile strength and flexure strength values. MPW fibres were shredded into 5-mm-, 10-mm- and 20 -mm-long fibres and mixed in concrete from 0 to $2 \%$ by volume of mix. Addition of MSW fibres results an increase in splitting tensile strength and ductility of concrete. However, the workability, compressive strength and flexural strength showed a negligible reduction at $1 \%$ dosage of MPW fibres. Up to $1 \%$ addition of waste by volume, the reduction in compressive strength was negligible, but beyond $1 \%$, addition reduction in compressive strength reaches to $9 \%$ and $11 \%$. Splitting tensile strength was increased from 21 and $33 \%$ up to $1 \%$ addition. For all test conditions, higher MPW dosage lowered workability. At increasing volume fractions, a higher MPW fibre dose raises the viscosity of the matrix and lowers the consistency of the concrete (Bhogayata et al. 2017). The purpose of this study was to see how employing plastic trash as a partial replacement for fine aggregate affected the fresh properties of selfcompacting concrete (SSC). Different self-compacting concrete mixes were created for this purpose, with a constant water-to-binder ratio of 0.32 and a binder content of $520 \mathrm{~kg} /$ $\mathrm{m}^{3}$. As a partial replacement for cement, class F fly ash was employed ( $30 \%$ by weight of cement). Experimental conditions included six distinct plastic waste contents of $0,2.5,5$, $7.5,10$ and $12.5 \%$, as well as three different sized plastic wastes (fine plastic wastes, coarse plastic wastes and mixed plastic waste). Slump flow diameter was used to test the workability qualities of self-compacting concrete mixtures. The compressive strength of concrete mixtures with plastic waste was lower than that of control mix without plastic waste. This could be due to the fact that plastic garbage is a softer substance than natural aggregate. $12.5 \%$ fine plastic 
waste, $12.5 \%$ coarse plastic waste and $12.5 \%$ mixed plastic waste all had compressive strengths of 47.0, 37.0 and $42 \mathrm{MPa}$, respectively (Hama et al. 2017). According to a review on use of various types of plastic on the fresh, mechanical and thermal properties of concrete, it was observed that workability, modulus of elasticity and compressive strength of concrete decrease but the tensile strength and flexural strength increase as the amount of plastic content increased (Sharma et al. 2016). The effects of size and shape of recycled plastic aggregates on workability were discovered in a review on the use of plastic waste aggregates in cement and concrete mortars. It was stated that the size and shape of aggregate used do not affect the strength of mortars but the strength of mortar decreases as the aggregate content increases. The flexure and splitting tensile strength improves to some level, as do the permeability and chemical resistance, according to the review (Yin et al. 2015). According to a research study on the use of plastic in concrete, the compressive, flexural and tensile strengths of concrete decrease as the proportion of plastic waste increases due to inadequate adhesive strength between the surface of the plastic aggregates (PA) and cement paste. The UPV (ultrasonic pulse velocity) of concrete, which represents its quality, falls as the plastic content increased. Plastic-containing concrete has a higher permeability than regular concrete. This concrete can be utilized in a variety of applications, including highway medians, highway pavement sub-bases and other constructions where strength is not a critical consideration. Several admixtures, such as super plasticizers, can be used to improve the workability of concrete containing plastic. As plastic does not mix well with natural aggregates, therefore water absorption, permeability and carbonation of concrete containing PA increase as the replacement ratio of fine aggregate (FA) increases, resulting in a porous matrix. Chloride penetration, on the other hand, is significantly reduced due to the impermeable plastic particles that prevent the chloride ion's passage (Almeshal et al. 2020). The effect of incorporating polypropylene (PP) as a partial replacement of natural stone aggregate (SA) and burnt clay brick aggregate (BA) was examined on the properties of concrete. PP was used in different percentages of $0 \%, 10 \%, 20 \%$ and $30 \%$ with water-cement ratio of 0.45 and 0.55 . Workability, hardened density, compressive and tensile strengths, modulus of rupture, modulus of elasticity (MoE), ultrasonic pulse velocity (UPV) and cost analysis were all examined. With raising the w/c ratio, the workability of stone aggregate concrete (SAC), brick aggregate concrete (BAC) and PP aggregate concrete (PAC) enhances. SAC has a density range of 2367 to $2096 \mathrm{~kg} / \mathrm{m}^{3}$, while BAC has a density range of 2075 to $1879 \mathrm{~kg} / \mathrm{m}^{3}$. When compared to normal concrete, concrete containing $10 \%$ PPA had stronger bonding between the aggregates and cement paste, resulting in a higher compressive strength. Compressive strength was found to be reduced with $20 \%$ and $30 \%$ PPA, respectively. The compressive strength of $50 \%$ of the specimens was over $20 \mathrm{MPa}$ and $18 \mathrm{MPa}$ for PP concrete with SA and BA, respectively, according to the cumulative distribution function (CDF) graph. The modulus of elasticity decreased by $1-47 \%$ for SAC and 5-36\% for BAC depending on the percentage of PPA and w/c ratios (Islam and Shahjalal 2021). Belmokaddem et al. examined the morphological, thermal, mechanical and acoustic properties of concrete made from three types of waste plastics (PP, HDPE and polyvinyl chloride (PVC)) and natural aggregate. Concrete with $75 \%$ plastic particles had a low dynamic modulus and thermal conductivity, according to the test results. At high replacement levels with $\mathrm{PP}$, the maximum reduction in hardened density was achieved; the value was $46 \%$ lower than that of reference concrete, i.e. $1318 \mathrm{~kg} / \mathrm{m}^{3}$. The compressive strength of concretes containing $\mathrm{PVC}, \mathrm{PP}$ and $\mathrm{PE}$ ranged from 12 to 26.9 $\mathrm{MPa}, 5.2$ to $25.4 \mathrm{MPa}$, and 4 to $19.5 \mathrm{MPa}$ at 28 days, respectively. In comparison to the values of reference concrete, the reduction in UPV ranged from 9.3 to $34.4 \%, 10.5$ to $47.6 \%$ and 11.9 to $48.7 \%$ for the PVC, PP and PE concrete mixes, respectively. Furthermore, the utilization of discarded plastic particles improved the acoustic qualities (Belmokaddem et al. 2020). The rheological, mechanical and durability properties of self-compacting concrete (SCC) were examined using waste polyethylene terephthalate (PET) particles and pozzolanic ingredients. The weight replacement ratios of fine aggregates with waste PET aggregates were used in the percentages of 5, 10 and $15 \%$, respectively, for replacing the same weight of fine aggregate. The cement replacement ratio was 10 and $30 \%$ keeping the weight of silica fume and fly ash same. Slump flow, V-funnel and L-box tests were used to examine the workability of SCC containing waste PET particles. Mechanical (compressive, tensile, and flexural strengths and modulus of elasticity) and rheological (L-box, slump flow and V-funnel) qualities, as well as durability (water absorption and electrical resistance) properties, were evaluated. The research suggests that waste PET particles can be employed as aggregates in a wide range of applications. Compressive, tensile and flexural strengths are all reduced when waste PET was used in SCC. Pozzolanic ingredients (fly ash and silica fume) compensate for the strength loss induced by the addition of PET. Waste PET has no effect on electrical resistance and makes concrete more fragile. The modulus of elasticity value decreased, and water absorption value increases by addition of waste PET (Sadrmomtazi et al. 2015). Faraj et al. explored the hardened properties of high-strength self-consolidating concrete (SCC) made using recycled polypropylene plastic particles (RPPP) and silica fume (SF). The cement content was $550 \mathrm{~kg} / \mathrm{m}^{3}$, with a maximum w/c ratio of 0.32 . RPPP was used to replace up to $40 \%$ of the natural aggregate. The fracture and durability properties of the concrete appeared to 
significantly increase, and the addition of SF improved the hardened properties of the concrete. For combinations without SF, increasing RPPP percentage from 0 to $40 \%$ lowered splitting tensile strength from 6.08 to $4.33 \mathrm{MPa}$. In addition, when the RPPP content was increased from 0 to $40 \%$ containing $10 \% \mathrm{SF}$, the splitting tensile strength reduced from 6.41 to $4.48 \mathrm{MPa}$. The results further showed that with an RPPP content of up to $40 \%$ replacement level by total medium aggregate volume (MAV) and $10 \%$ SF, SCC with compressive strength more than $70 \mathrm{MPa}$ at 90 days may be generated. The static elastic modulus was reduced by an average of $22 \%$ regardless of the SF content when the replacement amount of RPPP content was increased from 0 to $40 \%$. A concrete including RPPP may be used as structural concrete with a $70 \%$ reduction in cement and a $40 \%$ substitution of natural particles with plastic aggregates, according to the researchers.

In Table 2, optimum compressive strengths are reported with different compositions of plastic waste for concrete in road construction processes.

\section{Utilization of biomedical plastic waste in road construction}

Enormous amount of plastic wastes are generated in the medical field on a daily basis, for example, syringes, medicine wrappers, tubings, gloves, medicine bottles and bags. Therefore, there is a need to recycle such plastic waste as well. Few studies (Table 3) have reported the utilization of aldohexose bottles, syringes in bituminous mix construction. Bituminous mix prepared from drug plastic waste was then compared with ancient bituminous mix. Twelve plastic modified mix specimens were prepared with plastic proportion varied from 6, 8, 10 and $12 \%$ by weight of bitumen. Marshall methodology is adopted for mix designs. Various Marshall parameters like stability value, flow value and air voids were evaluated. The maximum flow value was observed to be $3.2 \mathrm{~mm}$ with $12 \%$ waste plastic. The optimum plastic content was found to be $9.33 \%$. Maximum stability was observed to be $24.77 \mathrm{kN}$ with $10 \%$ plastic content (Sunny 2018).

\section{Utilization of waste plastic with waste rubber in concrete/road construction}

Plastic waste in combination with rubber waste has been used to provide strength to rubber as well as the concrete. Table 4 presents the record of different compositions of plastic with rubber. It provides the detailed information and importance of plastic with rubber to enhance its applicability. To enhance the chemical properties of crumb rubber modified asphalt (CRMA), waste PET additives, derived through the associate degree aminolysis method, were used. It has been noted that the inclusion of these additives to CRMA increased the storage stability, rutting and fatigue resistance and inflated the rotational viscosity (RV) of the changed binders. The addition of bis(2hydroxy ethylene) terephthalamide (BHETA) to the rubber binders reduces the penetration values. Up to 3 to $5 \%$ BHETA addition, the consistency was comparatively little however on using 7\% of BHETA additive; the consistency considerably inflated. Crumb rubber changed with BHETA offered higher fatigue resistance. The addition of BHETA additives to CRMA inflated the stiffness and storage stability (Leng et al. 2018).

In a study, LDPE, HDPE and crumb rubber (CR) in percentages $(2,4,8$ and $10 \%$ by weight of bitumen) were mixed with base matrix of bitumen. The investigations on the viscous and elastic behaviour of binders at varied temperatures and frequencies revealed that the addition of plastic wastes, like LDPE, HDPE and CR, to binder improved the elastic behaviour of binder. It can extend the service life of pavements in terms of reduced susceptibility to rutting and cracking (Khan et al. 2016).

Admixtures of $2,4,6,8$ and $10 \%$ recycled plastic waste were used to modify $60 / 70$ penetration grade asphalt binder by wet method, whereas 1, 2, 3, 4 and 5\% crumb rubber was customized for mineral aggregates by dry method. It was observed that with the addition of $2 \%$ crumb rubber and 4\% LDPE, the Marshall stability value was found to be $30 \%$ more than the standard asphalt concrete mix. The LDPE changed asphalt binder showed a rise in viscosity, softening point and stiffness of binder (Onyango et al. 2015).

In a research study, bituminous mix was modified with plastic and rubber waste to be used in road construction. The modified bituminous mix was way stronger (61\%) than that of standard mix. Marshall quotient (MQ) was also enhanced by $52 \%$ as compared to the reference bituminous mix which indicated higher stiffness combined with an enhanced ability to bear the applied load and counter the deformation (Islam et al. 2016). Plastic waste like carry luggage, cups and tyres have been used for coating over aggregates. Polymer-coated aggregates have shown higher strength. Softening point exaggerated; however, the penetration value and malleability decrease with increase in amount of plastic waste. Polymer-coated aggregates show higher binding property and reduced air voids (Barad 2015). In another report, plastic waste and crumb rubber were used as a partial replacement of bitumen in the manufacturing of an amended binder for bituminous concrete mix. To replicate field conditions, Marshall stability analysis revealed that the bitumen modified with plastic waste and crumb rubber in certain proportion possess higher (Bansal et al. 2017). 


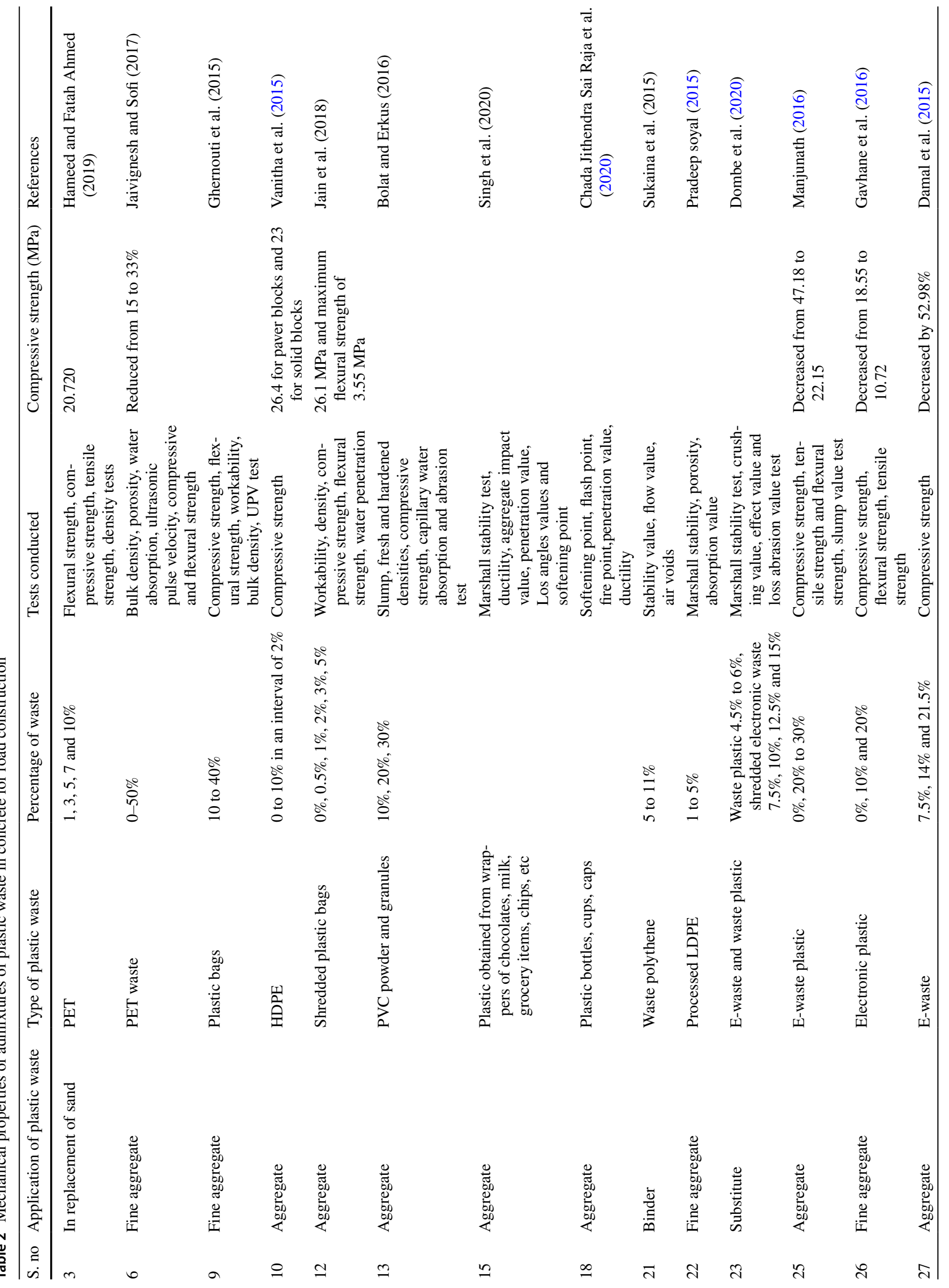




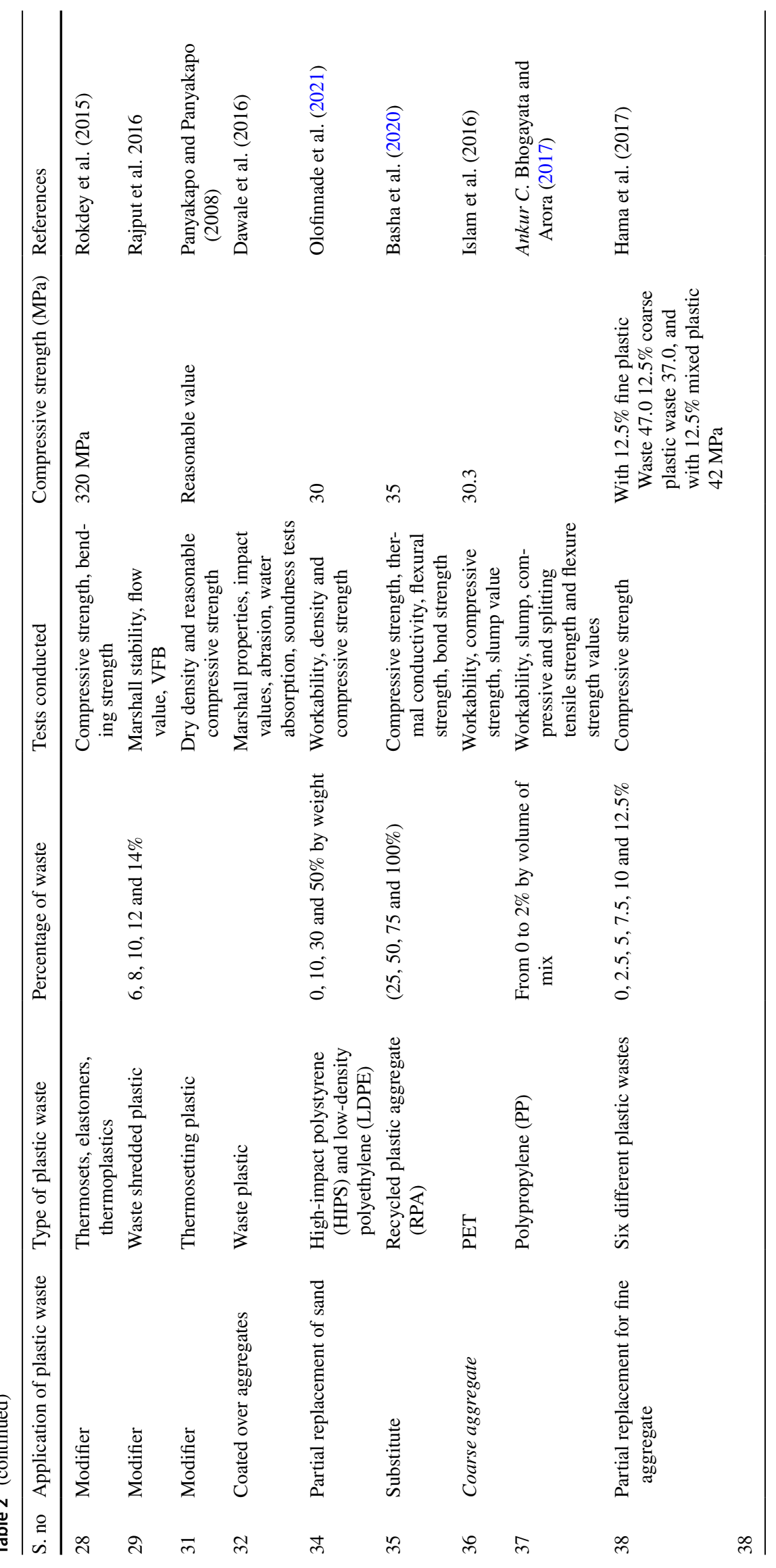


Table 3 Mechanical properties of admixtures of biomedical plastic waste for road construction

\begin{tabular}{|c|c|c|c|c|c|c|}
\hline S. no & Type of waste & $\%$ of waste & $\begin{array}{l}\text { Optimum plastic } \\
\text { content }\end{array}$ & Various tests & Test results & References \\
\hline 1 & $\begin{array}{l}\text { Glucose bottles, } \\
\text { syringes }\end{array}$ & $\begin{array}{l}6,8,10,12 \% \text { plastic } \\
\text { by weight of bitumen }\end{array}$ & $9.33 \%$ & $\begin{array}{l}\text { Stability value, flow } \\
\text { value, VFB and air } \\
\text { voids }\end{array}$ & $\begin{array}{c}\text { Marshall stability } \\
\text { value } 24.77 \mathrm{kN}\end{array}$ & Sunny (2018) \\
\hline
\end{tabular}

\section{Effect of percentage of waste plastic on the properties of concrete}

In concrete materials, mechanical properties particularly the strength behaviour are the decisive parameter outlining its suitability for practical applications. This section aims to recapitulate the effect of addition of waste plastic on the compressive strength, flexural strength and workability.

As is evident from the discussion in previous sections, addition of waste plastics from low to moderate replacement level resulted in an increase in compressive strength; however, higher level of replacement deteriorates the strength. This is shown in Fig. 4. Akinyele (2020) mixed PET with clay in fired bricks. Results show that with $0 \%, 5 \%, 10 \%$, $15 \%$ and $20 \%$ of PET, the compressive strength increases up to $2.30 \mathrm{MPa}$ with 5\% PET, and afterwards, it declines till $0.85 \mathrm{MPa}$ with 10\% PET. Azhdarpour (2016) replaced concrete fine aggregate by equivalent waste fragments, and results were taken after 3 days, 14 days and 28 days of curing. Compressive strength increases till $5 \%$ of waste plastic addition (21 MPa) followed by a decline. PET flakes were also used by replacing Portland cement (Hameed 2019). Of PET flakes, $1 \%, 3 \%, 5 \%, 7 \%$ and $10 \%$ are mixed, but the compressive strength was highest with $1 \%(20.720 \mathrm{MPa})$ only. Ikechukwo (2021) used melted PET with recycled crushed glass in masonry bricks. At 20\%, the compressive strength was $33.45 \mathrm{MPa}$, and at $30 \%$, the compressive strength was $43.14 \mathrm{MPa}$. But at $40 \%$, compressive strength decreased up to $38.25 \mathrm{MPa}$. When shredded plastic was mixed with soil for compressed earth bricks (CEB) (Akinwumi, 2019), the compressive strength increased with $1 \%$ composition (1.098 MPa) as compared to control $(0.45 \mathrm{MPa})$. On the 28th day, the compressive strength was almost equal to $2.5 \%, 3.0 \%$ and $3.5 \%$ of HDPE (12.5 MPa/12.6 MPa) (Ali 2017). These results indicate that at first, the compressive strength exhibits an increase with the addition of waste plastic but after a certain percentage, it declines. Most of the researchers have reported similar behaviour. They have attributed this behaviour to the stress redistribution at low to moderate percentage replacement. As the percentage of plastic waste increases, non-uniformity of concrete, huge voids, less fluidity, etc. influence the compaction. Also the presence of huge voids results in increased stresses at the plastic concrete interface, leading to a decrease in strength. Though there is no definite pattern of increase or decline in strength corresponding to the percentage replacement, the acceptable range of addition of plastic waste is $5-30 \%$, by weight corresponding to which maximum compressive strength of $43.14 \mathrm{MPa}$ can be obtained. The strength behaviour also has a significant dependence on the pre-treatment of plastic waste. Another important property is the workability of concrete. Addition of waste plastics reduces the workability of concrete which is measured in terms of slump value. Bhogayata et al. (2017) detected up to $25 \%$ decline in workability for the $2 \%$ of polythene plastic pieces. However, at low percentage, the decline in workability suffices the acceptable range of slump values. Though many properties show a decline by the addition of waste plastic, the above reported studies show an increment in the flexural strength (Seghiri et al. 2017, Hameed and Fatah Ahmed 2019, Azhdarpour et al. 2016).

For road construction, combination of waste plastic and waste rubber is showing beneficial properties. Addition of plastic by $10 \%$ in conjunction with waste rubber has improved elastic properties and reduced susceptibility to rutting and cracking (Khan et al. 2016).

\section{Future scope of work}

Clearly, plastic waste can prove to be a sustainable additive and partial replacement of conventional construction materials thereby addressing the dual issue of management of plastic waste and helping in the reduction of footprints caused by construction industry on the environment. However, a long road is ahead before the commercial implementation of the idea can be realized. More research is required to fully understand the advantages and limitations of plastic wastebased construction material qualitatively and quantitatively. Several issues to be addressed for commercialization and for future research are:

- Optimum proportions of plastic waste as a constituent of construction materials are required.

- Safe methods of sanitization of plastic waste in order to eliminate the potential contaminants.

- Analysis of carbon life cycle to reinforce the claim for sustainability.

- Cost-benefit analysis for the commercial production of such construction material. 


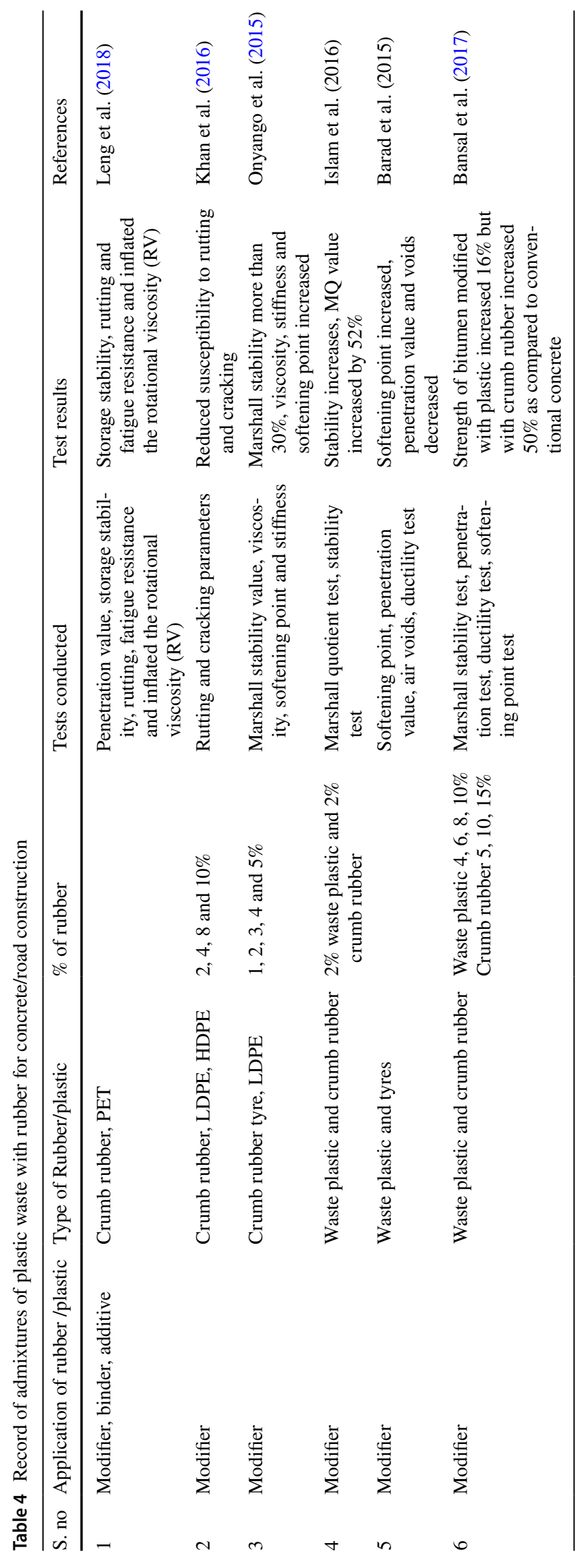


Fig. 4 Effect of the percentage of waste plastic on the compressive strength of concrete

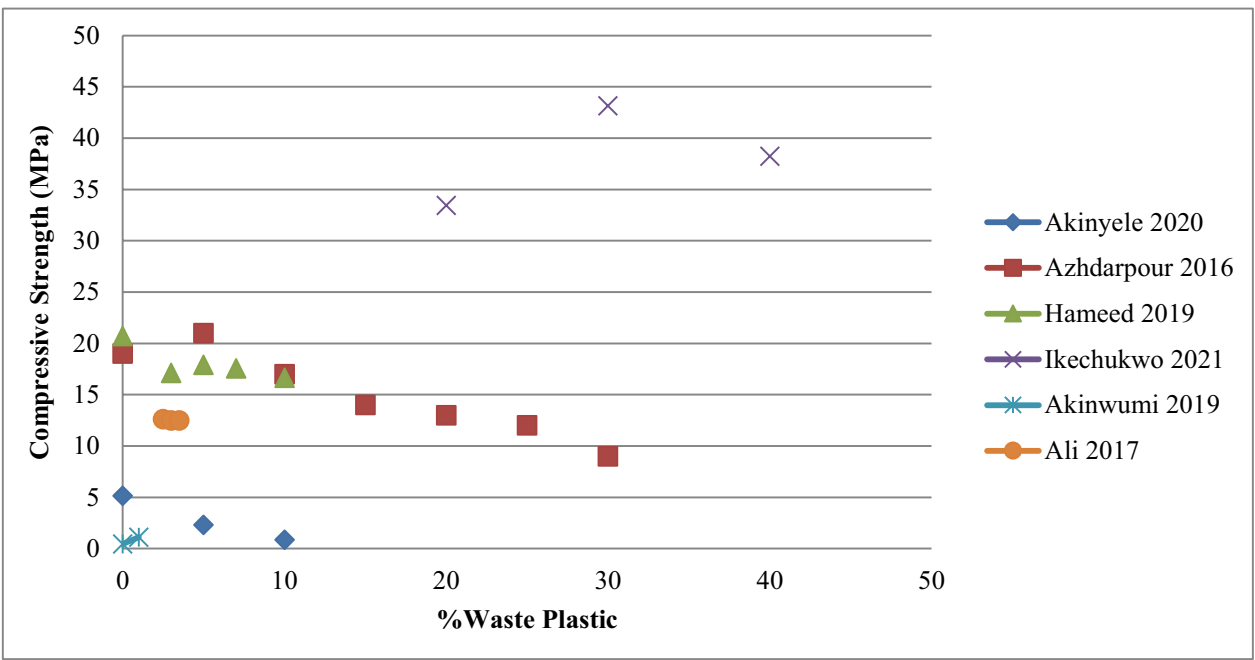

- Dedicated standards to evaluate the quality of plastic waste-based construction material.

- Public awareness drives to communicate about the environmental and economic advantages of wastebased construction material are required for its acceptance by consumers and public in general.

\section{Conclusion}

Growing amounts of plastic waste in our ecosystem can be strategically tackled by its recycling/reuse in an effective and beneficial manner. This review gave a focussed summary of the research work being carried out to exploit plastic waste as a constituent of construction material. It is a meticulous study of utilization of waste plastic in construction bricks, blocks, tiles and concrete for road construction. It also touches the usage of medical plastic waste and admixtures of plastic waste with waste rubber in construction materials. On the basis of such an extensive study, the following are the conclusions:

- Plastic waste from PET, PVC, PU, LDPE, HDPE, nylon 66 , etc. can be efficiently used in conjunction with fly ash, sand, cement and other materials for the production of bricks, blocks and tiles. However, PET waste is a favourable replacement.

- Lightweight concrete containing $10 \%$ of HIPS and LDPE plastic wastes attained $30 \mathrm{~N} / \mathrm{mm}^{2}$ compressive strength after 28 days of curing.

- Workability of the concrete decreases with increasing percentage of plastic; however, it can be maintained to some extent by increasing the water/cement ratio (w/c) ratio.
- Workability of plastic waste-based concrete depends significantly on the size, shape and roughness of plastic aggregates and water-cement ratio.

- Inclusion of waste plastic decreases the modulus of elasticity of concrete.

- Plastic waste-based concrete possessed greater resistance to chloride ion penetration and less shrinkage on drying.

- Recycled plastic aggregates can successfully be used in concrete bricks/pavement blocks non-structural panels.

- Concrete containing waste plastic bottles is useful in making temporary shelters.

- Plastic waste-based concrete can be highly useful for low load-bearing structures such as partitions and decorative tiles.

- Mix of waste plastic with crumb rubber acts as modifier and binder in road construction.

Acknowledgements The authors acknowledge the support received from the leadership and management of K.R. Mangalam University, Gurugram, Haryana.

Author contributions Idea for the article: Dilraj Preet Kaur, Seema Raj. Literature search and data analysis: Pooja Lamba, Jyoti Sorout. Drafted and/or critically revised the work: Dilraj Preet Kaur, Seema Raj, Pooja Lamba.

Data availability Not applicable.

\section{Declarations}

Ethics approval and consent to participate This article does not include any studies with human participants or animals performed by any of the authors.

Consent for publication Not applicable.

Competing interests The authors declare no competing interests. 


\section{References}

Abdel Tawab OF, Amin MR, Ibrahim MM, Abdel Wahab M, Abd El Rahman EN, et al. (2020) Recycling waste plastic bags as a replacement for cement in production of building bricks and concrete blocks. Journal of Waste Resources and Recycling, Vol.-1(2) pp-1-13

Akinwumi II, Domo-Spiff AH, Salami A (2019) Marine plastic pollution and affordable housing challenge: shredded waste plastic stabilized soil for producing compressed earth bricks. Case Studies in Construction Materials 11:e00241. https://doi.org/10.1016/j. cscm.2019.e00241

Akinyele JO, Igba UT, Adigun BG (2020) Effect of waste PET on the structural properties of burnt bricks. Scientific African 7:e00301. https://doi.org/10.1016/j.sciaf.2020.e00301

Alaloul WS, John VO, Musarat MA (2020) Mechanical and thermal properties of interlocking bricks utilizing wasted polyethylene terephthalate. Int J Concr Struct Mater 14:24. https://doi.org/10. 1186/s40069-020-00399-9

Noorwirdawati Ali et al, Compressive strength and initial water absorption rate for cement brick containing high-density polyethylene (HDPE) as a substitutional material for sand, IOP Conf. Series: Materials Science and Engineering 271 (2017) 012083. https:// doi.org/10.1088/1757-899X/271/1/012083

Almeshal I, Tayeh BA, Alyousef R, Alabduljabbar H, Abdeliazim Mustafa Mohamed, Abdulaziz Alaskar, Use of recycled plastic as fine aggregate in cementitious composites: a review, https:// doi.org/10.1016/j.conbuildmat.2020.119146

Alqahtani FK, Ghataora G, Dirar S et al (2018) Experimental study to investigate the engineering and durability performance of concrete using synthetic aggregates. Constr Build Mater 173:350-358. https://doi.org/10.1016/j.conbuildmat.2018.04.018

Ameri M, Nasr D (2016) Properties of asphalt modified with devulcanized polyethylene terephthalate. Pet Sci Technol 34:1424-1430. https://doi.org/10.1080/10916466.2016.1202968

Aneke FI, Shabangu C (2021) Green-efficient masonry bricks produced from scrap plastic waste and foundry sand. Case Studies in Construction Materials 14:e00515. https://doi.org/10.1016/j. cscm.2021.e00515

Awoyera PO, Adesina A (2020) Plastic wastes to construction products: status, limitations and future perspective. Case Studies in Construction Materials 12:e0330. https://doi.org/10.1016/j.cscm. 2020.e00330

Azhdarpour AM, Nikoudel MR, Taheri M (2016) The effect of using polyethylene terephthalate particles on physical and strengthrelated properties of concrete; a laboratory evaluation. Constr Build Mater 109:55-62. https://doi.org/10.1016/j.conbuildmat. 2016.01.056

Babafemi A, Šavija B, Paul S, Anggraini V (2018) Engineering properties of concrete with waste recycled plastic: a review. Sustainability 10:3875. https://doi.org/10.3390/su10113875

Bahoria BV, Parbat DK, Nagarnaik PB (2017) Effect of characterization properties on compressive strength of concrete containing quarry dust and waste plastic as fine aggregate. International Journal of Civil Engineering and Technology (IJCIET) 8:699-707

Bansal S, Kumar Misra A, Bajpai P (2017) Evaluation of modified bituminous concrete mix developed using rubber and plastic waste materials. Int J Sustain Built Environ 6:442-448. https://doi.org/ 10.1016/j.ijsbe.2017.07.009

Barad M M (2015) Use of plastic in bituminous road construction. Journal of information 3:pp.208-212

Shaik Inayath Basha, M.R. Ali, S.U. Al-Dulaijan, M. Maslehuddin, Mechanical and thermal properties of lightweight recycled plastic aggregate concrete, Journal of Building Engineering 32 (2020) 101710, pp-1-14, https://doi.org/10.1016/j.jobe.2020.101710
Behera D (2018) Experimental investigation on recycling of plastic wastes and broken glass in to construction material. International Journal of Creative Research Thoughts 6:1659-1667. https://doi.org/10.1727/IJCRT.17232

Bejan G, Bărbuță M, Ștefan VR, Burlacu A (2020) Lightweight concrete with waste - review. Procedia Manufacturing 46:136-143. https://doi.org/10.1016/j.promfg.2020.03.021

M. Belmokaddem, A. Mahi, Y. Senhadji, B.Y. Pekmezci, Mechanical and physical. properties and morphology of concrete containing plastic waste as aggregate, Construct. Build. Mater. 257 (2020), 119559, https://doi.org/10.1016/j.conbuildmat.2020.119559

Bhogayata AC, Arora NK (2017) Fresh and strength properties of concrete reinforced with metalized plastic waste fibers. Constr Build Mater 146(2017):455-463. https://doi.org/10.1016/j. conbuildmat.2017.04.095

Bolat H, Erkus P (2016) Use of polyvinyl chloride (PVC) powder and granules as aggregate replacement in concrete mixtures. Sci Eng Compos Mater 23:209-216. https://doi.org/10.1515/ secm-2014-0094

Chaudhary M, Srivastava V, Agarwal VC (2014) Effect of waste low density polyethylene on mechanical properties of concrete. 3:4

Choi N-W, Mori I, Ohama Y (2006) Development of rice husks-plastics composites for building materials. Waste Manage 26:189194. https://doi.org/10.1016/j.wasman.2005.05.008

Dalhat MA, Al-Abdul Wahhab HI (2016) Cement-less and asphaltless concrete bounded by recycled plastic. Constr Build Mater 119:206-214. https://doi.org/10.1016/j.conbuildmat.2016.05. 010

Damal VS, Londhe SS, Mane AB (2015) Utilization of electronic waste plastic in concrete. 5:pp.35-38

Dawale (2016) Use of waste plastic coated aggregates in bituminous road construction. In: fdocuments.in. https://fdocuments.in/docum ent/use-of-waste-plastic-coated-aggregates-in-bituminous-roadconstruction.html. Accessed 13 May 2021

Dombe S, Tapase AB, Ghugal YM, Konnur BA, Akshay P (2020) Investigation on the use of $\mathrm{E}$-waste and waste plastic in road construction. Environmental Science 85-99, https://doi.org/10.1007/ 978-3-030-34196-1_6

Gavhane A, Sutar D, Soni S, Patil P (2016) Utilisation of E-plastic waste in concrete. International Journal of Engineering Research \& Technology (IJERT) 5:594-601

Gu L, Ozbakkaloglu T (2016) Use of recycled plastics in concrete: a critical review. Waste Manage 51:19-42. https://doi.org/10.1016/j. wasman.2016.03.005

Hama SM, Hilal NN (2017) Fresh properties of self-compacting concrete with plastic waste as partial replacement of sand. Int J Sustain Built Environ 6(2017):299-308. https://doi.org/10.1016/j. ijsbe.2017.01.001

Hameed AM, Fatah Ahmed BA (2019) Employment the plastic waste to produce the light weight concrete. Energy Procedia 157:30-38. https://doi.org/10.1016/j.egypro.2018.11.160

Haque MdS (2019) Sustainable use of plastic brick from waste PET plastic bottle as building block in Rohingya refugee camp: a review. Environmental Science and Pollution Research 26: https:// doi.org/10.1007/s11356-019-06843-y

Hemalatha D (2019) Reuse of waste plastics and demolition waste in the development of plastic paver block. J Sci Ind Res 78:248-250

Hossain M, Bhowmik P, Shaad K (2016) Use of waste plastic aggregation in concrete as a constituent material. Progress Agric 27:383391. https://doi.org/10.3329/pa.v27i3.30835

Ikechukwu AF, Shabangu C (2021) Strength and durability performance of masonry bricks produced with crushed glass and melted PET plastics. Case Studies in Construction Materials 14:e00542. https://doi.org/10.1016/j.cscm.2021.e00542

Jahidul Islam Md, Shahjalal Md (2021) Effect of polypropylene plastic on concrete properties as a partial replacement of stone 
and brick aggregate. Case Studies in Construction Materials 15:1-21. https://doi.org/10.1016/j.cscm.2021.e00627

Jahidul Islam Md, Salamah Meherier Md, Rakinul Islam AKM (2016) Effects of waste PET as coarse aggregate on the fresh and harden properties of concrete. Constr Build Mater 125(2016):946-951. https://doi.org/10.1016/j.conbuildmat. 2016.08.128

Jain A, Siddique S, Gupta T (2019) Fresh, strength, durability and microstructural properties of shredded waste plastic concrete. Iran J Sci Technol Trans Civ Eng 43:455-465. https://doi.org/10.1007/ s40996-018-0178-0

Jaivignesh B, Sofi A (2017) Study on mechanical properties of concrete using plastic waste as an aggregate. IOP Conf Ser: Earth Environ Sci 80:012016. https://doi.org/10.1088/1755-1315/80/1/012016

Kazmi S, Rao DG (2015) Utilization of waste plastic materials as bitumen-blends for road construction in Oman. Scholars Journal of Engineering and Technology (SJET) 3:9-13

Khan IM, Kabir S, Alhussain MA, Almansoor FF (2016) Asphalt design using recycled plastic and crumb-rubber waste for sustainable pavement construction. Procedia Engineering 145:1557-1564. https://doi.org/10.1016/j.proeng.2016.04.196

Kognole R, Shipkule K, Survase K (2019) Utilization of plastic waste for making plastic bricks. International Journal of Trend in Scientific Research and Development 3:878-880. https://doi.org/10. 31142/ijtsrd23938

Kumi-Larbi A, Yunana D, Kamsouloum P et al (2018) Recycling waste plastics in developing countries: use of low-density polyethylene water sachets to form plastic bonded sand blocks. Waste Manage 80:112-118. https://doi.org/10.1016/j.wasman.2018.09.003

Lalzarliana Paihte P, Lalngaihawma AC, Saini G (2019) Recycled aggregate filled waste plastic bottles as a replacement of bricks. Materials Today: Proceedings 15:663-668. https://doi.org/10. 1016/j.matpr.2019.04.135

Leela Bharathi SM, Johnpaul V, Praveen Kumar R, et al. (2020) Experimental investigation on compressive behaviour of plastic brick using $\mathrm{M}$ sand as fine aggregate. Materials Today: Proceedings S2214785320378585. https://doi.org/10.1016/j.matpr.2020.10. 252

Leng Z, Padhan RK, Sreeram A (2018) Production of a sustainable paving material through chemical recycling of waste PET into crumb rubber modified asphalt. J Clean Prod 180:682-688. https://doi. org/10.1016/j.jclepro.2018.01.171

Li X, Ling T-C, Hung Mo K (2020) Functions and impacts of plastic/ rubber wastes as eco-friendly aggregate in concrete - a review. Constr Build Mater 240:117869. https://doi.org/10.1016/j.conbu ildmat.2019.117869

Li Y, White DJ, Lee Peyton R (1998) Composite material from fly ash and post-consumer PET. Res Conserv Recyc 24:87-93. https:// doi.org/10.1016/S0921-3449(98)00041-X

Limami H, Manssouri I, Cherkaoui K, Saadaoui M, Khaldoun A (2020a) Thermal performance of unfired lightweight clay bricks with HDPE \& PET waste plastics additives. Journal of Building Engineering 30(101251):1-12. https://doi.org/10.1016/j.jobe. 2020.101251

Limami H, Manssouri I, Cherkaoui K, Khaldoun A (2020b) Study of the suitability of unfired clay bricks with polymeric HDPE \& PET wastes additives as a construction material. Journal of Building Engineering 27:100956. https://doi.org/10.1016/j.jobe. 2019.100956

Manju R, Sheema K, Sathya S (2017) Use of plastic waste in bituminous pavement. Int J ChemTech Res 10:804-811

Manjunath BTA (2016) Partial replacement of E-plastic waste as coarse-aggregate in concrete. Procedia Environ Sci 35:731-739. https://doi.org/10.1016/j.proenv.2016.07.079
Mansour AMH, Ali SA (2015) Reusing waste plastic bottles as an alternative sustainable building material. Energy Sustain Dev 24:79-85. https://doi.org/10.1016/j.esd.2014.11.001

Mercante I, Alejandrino C, Ojeda JP et al (2018) Mortar and concrete composites with recycled plastic: a review. Science and Technology of Materials 30:69-79. https://doi.org/10.1016/j.stmat.2018. 11.003

Mokhtar M, Sahat S, Hamid B, Kaamin M, Kesot MJ, Wen LC, Xin LY, Ling NP, Jia Lei VS (2016) Appication of plastic bottle as a wall structure for green house. ARPN J Eng Appl Sci 11(12):7617-7621

Mondal MK, Bose BP, Bansal P (2019) Recycling waste thermoplastic for energy efficient construction materials: an experimental investigation. J Environ Manage 240:119-125. https://doi.org/10. 1016/j.jenvman.2019.03.016

Monish K, Jesuran JJ, Kolathayar S (2021) A sustainable approach to turn plastic waste into useful construction blocks. pp 55-62. https://doi.org/10.1007/978-981-15-5001-0_5

Nair V, Kvr P, SP M, et al. (2013) Study on utilization of waste plastic in bituminous mixes for road construction

Nikoo Haghighatnejad S, Yasin Mousavi S, Khaleghi J, Tabarsa A, Yousefi S (2016) Properties of recycled PVC aggregate concrete under different curing conditions. Constr Build Mater 126:943950. https://doi.org/10.1016/j.conbuildmat.2016.09.047

Ogundairo TO, Olukanni DO, Akinwumi II, Adegoke DD (2021) A review on plastic waste as sustainable resource in civil engineering applications. IOP Conf Ser: Mater Sci Eng 1036:012019. https://doi.org/10.1088/1757-899X/1036/1/012019

Olofinnade O, Chandra S, Chakraborty P, Today M (2021) Proceedings, Recycling of high impact polystyrene and low-density polyethylene plastic wastes in lightweight based concrete for sustainable construction, Volume 38. Part 5:2151-2156. https://doi.org/ 10.1016/j.matpr.2020.05.176

Onyango F, Wanjala SR, Ndege M, Masu L (2015) Effect of rubber tyre and plastic wastes use in asphalt concrete pavement. International Journal of Civil and Environmental Engineering 9:1403-1407

Pelisser F, Montedo ORK, Gleize PJP, Roman HR (2012) Mechanical properties of recycled PET fibers in concrete. Mat Res 15:679686. https://doi.org/10.1590/S1516-14392012005000088

Puttaraj M, Hiremath S, Shetty N et al (2018) Utilization of waste plastic in manufacturing of plastic-soil bricks. International Journal of Technology Enhancements and Emerging Engineering Research 2:102-107

Rabar H. Faraj, A.F.H. Sherwani, A. Daraei, Mechanical, fracture and durability properties of self-compacting high strength concrete containing recycled polypropylene plastic particles, J. Build. Eng. 25 (2019), 100808. https://doi.org/10.1016/j.jobe.2019.100808

Raja CJS, Sai Sampath N, Su Chesh A, Bhaskar Phani (2020) A review on use of plastic in construction of roads. Journal of Advancement in Engineering and Technology. https://doi.org/10.5281/ ZENODO.3780333

Rajput PS, Yadav RK (2016) Use of plastic waste in bituminous road construction. International Journal of Science Technology \& Engineering 2:509-513

Sadrmomtazi A, Dolati-Milehsara S, Lotfi-Omran O, Sadeghi-Nik A (2015), The combined effects of waste PET particles and pozzolanic materials on the properties of self-compacting concrete. Journal of Cleaner Production. https://doi.org/10.1016/j.jclepro. 2015.09.107

Safinia S, Alkalbani A (2016) Use of recycled plastic water bottles in concrete blocks. Procedia Engineering 164:214-221. https://doi. org/10.1016/j.proeng.2016.11.612

Salih MM, Osofero AI, Imbabi MS (2020) Critical review of recent development in fiber reinforced adobe bricks for sustainable construction. Front Struct Civ Eng 14:839-854. https://doi.org/10. 1007/s11709-020-0630-7 
Salunkhe TV, Mandal JN Behavior of fly ash at different mix ratios with plastic recycled polymers. 11

Seghiri M, Boutoutaou D, Kriker A, Hachani MI (2017) The possibility of making a composite material from waste plastic. Energy Procedia 119:163-169. https://doi.org/10.1016/j.egypro.2017.07.065

Sellakutty D, Dinesh A, Kirubakaran K (2016) Utilization of waste plastic in manufacturing of bricks and paver blocks. International Journal of Applied Engineering Research 16:364-368

Selvamani GD, Sabarish P, Thulasikanth Y, Vinoth Kumar E (2019) Preparation of bricks using sand and waste plastic bottles. International Research Journal in Advanced Engineering and Technology (IRJAET) 5:4341-4352

Shah R, Garg H, Gandhi P, et al. Study of plastic dust brick made from waste plastic. 5:4

Sharma R, Bansal PP (2016) Use of different forms of waste plastic in concrete-a review. J Cleaner Prod 112:473-482. https://doi.org/ 10.1016/j.jclepro.2015.08.042

Singh S, Dwivedi SP, Kumar A (2021) A critical review on the utilization of waste PET and marble dust in the development of composite material. Materials Today: Proceedings. https://doi.org/10. 1016/j.matpr.2021.04.535

Singhal A, Omprakash Netula D (2018) Utilization of plastic waste in manufacturing of plastic sand bricks. Conference Proceeding of 3rd International Conference on New Frontiers of Engineering, Science, Management and Humanities (ICNFESMH-2018),207-210

Pranav Sonone, Rajanikant Devalkar (2017) Green sustainable bricks made of fly ash and discarded polyethylene waste. International Journal of Innovative Research in Science, Engineering and Technology 6:6509-6516, https://doi.org/10.15680/IJIRSET.2017. 0604063

Soyal P (2015) Use of waste polythene in bituminous concrete mixes. International Research Journal of Engineering and Technology (IRJET), 2:1114-1116

Suganya S (2015) A study on mechanical properties of fly ash brick with waste plastic strips. International Journal of Applied Engineering Research 10 :

Taaffe J, O'Sullivan S, Rahman ME, Pakrashi V (2014) Experimental characterization of Polyethylene Terephthalate (PET) bottle Ecobricks. Mater Design 60:50-56. https://doi.org/10.1016/j.matdes. 2014.03.045

Tina Maria Sunny (2018) Use of biomedical plastic waste in bituminous road construction. 5:76-82
Tiwari A, Singh S, Nagar R (2016) Feasibility assessment for partial replacement of fine aggregate to attain cleaner production perspective in concrete: a review. J Clean Prod 135:490-507. https:// doi.org/10.1016/j.jclepro.2016.06.130

Toghroli A, Shariati M, Sajedi F, et al. (2018) A review on pavement porous concrete using recycled waste materials. Smart Structures and Systems 22:433-440. https://doi.org/10.12989/SSS.2018. 22.4.433

Vanitha S, Natarajan V, Praba M (2015) Utilisation of waste plastics as a partial replacement of coarse aggregate in concrete blocks. Indian Journal of Science and Technology 8:. https://doi.org/10. 17485/ijst/2015/v8i12/54462

Velmurugan V (2019) Rebuilding of plastic waste to pavement bricks. IJRASET 7:927-931. https://doi.org/10.22214/ijraset.2019.4165

Vishnu TB, Singh KL (2020) A study on the suitability of solid waste materials in pavement construction: a review. International Journal of Pavement Research and Technology, 1-13, https://doi.org/ 10.1007/s42947-020-0273-z

Owolabi Wahab Folorunsho and Akobundu Nwanosike Amad, Production of pavement blocks from plastic waste, The Pacific Journal of Science and Technolog, Volume 21. Number 2. November 2020, PP-36-43

Yang S, Yue X, Liu X, Tong Y (2015) Properties of self-compacting lightweight concrete containing recycled plastic particles. Constr Build Mater 84:444-453. https://doi.org/10.1016/j.conbuildmat. 2015.03.038

Yin S, Tuladhar R, Shi F, Combe M, Collister T, Sivakugan N (2015) Use of macro plastic fibres in concrete: a review. Constr Build Mater 93:180-188. https://doi.org/10.1016/j.conbuildmat.2015. 05.105

Zulkernain NH, Gani P, Chuck Chuan N, Uvarajan T (2021) Utilisation of plastic waste as aggregate in construction materials: a review. Constr Build Mater 296:123669. https://doi.org/10.1016/j.conbu ildmat.2021.123669

Publisher's note Springer Nature remains neutral with regard to jurisdictional claims in published maps and institutional affiliations. 